\title{
An inventory of active subglacial lakes in Antarctica detected by ICESat (2003-2008)
}

\author{
Benjamin E. SMITH, ${ }^{1}$ Helen A. FRICKER, ${ }^{2}$ Ian R. JOUGHIN, ${ }^{1}$ Slawek TULACZYK ${ }^{3}$ \\ ${ }^{1}$ Applied Physics Laboratory, University of Washington, 1013 NE 40th Street, Box 355640, Seattle, \\ Washington 98105-6698, USA \\ E-mail: bsmith@apl.washington.edu \\ ${ }^{2}$ Institute of Geophysics and Planetary Physics, Scripps Institution of Oceanography, University of California-San Diego, \\ La Jolla, California 92093-0225, USA \\ ${ }^{3}$ Department of Earth and Planetary Sciences, University of California Santa Cruz, Santa Cruz, California 95064, USA
}

\begin{abstract}
Through the detection of surface deformation in response to water movement, recent satellite studies have demonstrated the existence of subglacial lakes in Antarctica that fill and drain on timescales of months to years. These studies, however, were confined to specific regions of the ice sheet. Here we present the first comprehensive study of these 'active' lakes for the Antarctic ice sheet north of $8^{\circ} \mathrm{S}$, based on 4.5 years (2003-08) of NASA's Ice, Cloud and land Elevation Satellite (ICESat) laser altimeter data. Our analysis has detected 124 lakes that were active during this period, and we estimate volume changes for each lake. The ICESat-detected lakes are prevalent in coastal Antarctica, and are present under most of the largest ice-stream catchments. Lakes sometimes appear to transfer water from one to another, but also often exchange water with distributed sources undetectable by ICESat, suggesting that the lakes may provide water to or withdraw water from the hydrologic systems that lubricate glacier flow. Thus, these reservoirs may contribute pulses of water to produce rapid temporal changes in glacier speeds, but also may withdraw water at other times to slow flow.
\end{abstract}

\section{INTRODUCTION}

Most of our knowledge of subglacial lakes in Antarctica has come from ice-penetrating radio-echo sounding (RES) surveys since the 1950s (Robin and others, 1970). The most recent subglacial lake inventory reported 145 lakes (Siegert and others, 2005); however, more than 130 have been added since then (Siegert and others, 2005; Bell and others, 2007; Carter and others, 2007; Popov and Masolov, 2007), and at the time of writing there are $\sim 280$ subglacial lakes that have been identified using RES, the majority of these under the plateau of the East Antarctic ice sheet.

It has long been known that the dynamics of much of the Antarctic ice sheet is largely controlled by meltwater at the ice-sheet bed (Budd and others, 1984). The configuration of many large outlet glacier systems is known to depend on the presence of water-saturated sediments (Studinger and others, 2001), which can reduce the basal shear stress from frozen-bed values $(\sim 100 \mathrm{kPa})$ to values which permit rapid ice flow at low driving stresses ( $20 \mathrm{kPa})$ (Kamb, 2001). Likewise, changes in water pressure and volume can lead to changes in basal lubrication. This has been observed in mountain glaciers, where the accumulation of large volumes of water drives surges during which surface velocities briefly increase by an order of magnitude or more (e.g. Kamb and others, 1985), and where episodic and seasonal water inputs can also modulate ice-flow rates (Harper and others, 2007). Seasonal acceleration resulting from surface meltwater reaching the bed has also been observed on the Greenland ice sheet (Zwally and others, 2002; Howat and others, 2008; Joughin and others, 2008). The movement of water beneath ice sheets is one of the few processes that can drive large changes in outlet glacier speeds on short timescales (Truffer and Fahnestock, 2007). Conversely, reduced amounts of subglacial water can lead to lower flow speeds; indeed, re-routing of subglacial water flow has been proposed as a cause of the late-19th-century stagnation of the trunk of Kamb Ice Stream, West Antarctica (Anandakrishnan and Alley, 1997).

In Antarctica, where surface melt is rare and the ice-sheet bed is insulated from surface temperature changes by the thick ice cover, subglacial water flow was, until recently, thought to be steady and subglacial hydrology was understood to evolve principally in response to changes in (1) pressure gradients resulting from ice-thickness changes (e.g. Anandakrishnan and Alley, 1997), and (2) water production due to changes in basal sliding speeds and ice thickness (e.g. Bougamont and others, 2003a). These mechanisms were thought to have produced changes in ice-flow configuration over decades (e.g. Joughin and others, 2005), but were not expected to result in abrupt ice-flow changes. The recent discovery of active subglacial lakes in Antarctica (Gray and others, 2005; Wingham and others, 2006; Fricker and others, 2007) has changed our conceptual understanding of the ice sheet's subglacial hydrological system. Large subglacial reservoirs have been found under ice streams and outlet glaciers through detection of vertical motion of the ice-sheet surface in response to subglacial water motion, and the lake volumes have been found to change on annual or shorter timescales. The largest of these, 'Subglacial Lake Engelhardt', was about $30 \mathrm{~km}$ long and $10 \mathrm{~km}$ wide, and was revealed in repeat-track Ice, Cloud and land Elevation Satellite (ICESat) laser altimeter data, by an ice surface draw-down of $9 \mathrm{~m}$ over almost 3 years, releasing a flood of $\sim 2.0 \mathrm{~km}^{3}$ of water (Fricker and others, 2007). These relatively abrupt changes in water volume at the bed may provide a temporally variable source of water to change ice speeds over annual or sub-annual periods, as was observed in the Byrd Glacier system, where the drainage of $1.7 \mathrm{~km}^{3}$ of lake water has been linked to enhanced ice-flow rates (10\%) 
Table 1. Acquisition dates for the 13 ICESat campaigns acquired over a 33 day subcycle of the standard 91 day reference orbit up to March 2008. Note that data from campaign 2c (May-June 2004) are not used because of relatively poor data quality. Dates are formatted: month/day/year+2000

\begin{tabular}{lcc}
\hline Campaign & Start & End \\
\hline 2a & & \\
2b & $10 / 4 / 03$ & $11 / 19 / 03$ \\
2c & $2 / 17 / 04$ & $3 / 21 / 04$ \\
$3 \mathrm{a}$ & $5 / 18 / 04$ & $6 / 21 / 04$ \\
$3 \mathrm{~b}$ & $10 / 3 / 04$ & $11 / 8 / 04$ \\
$3 \mathrm{c}$ & $2 / 17 / 05$ & $3 / 24 / 05$ \\
$3 \mathrm{~d}$ & $5 / 20 / 05$ & $6 / 23 / 05$ \\
$3 \mathrm{e}$ & $10 / 21 / 05$ & $11 / 24 / 05$ \\
$3 \mathrm{f}$ & $2 / 22 / 06$ & $3 / 28 / 06$ \\
$3 \mathrm{~g}$ & $5 / 24 / 06$ & $6 / 26 / 06$ \\
$3 \mathrm{~h}$ & $10 / 25 / 06$ & $11 / 27 / 06$ \\
$3 \mathrm{i}$ & $3 / 12 / 07$ & $4 / 14 / 07$ \\
$3 \mathrm{j}$ & $10 / 2 / 07$ & $11 / 5 / 07$ \\
& $2 / 17 / 08$ & $3 / 21 / 08$ \\
\hline
\end{tabular}

that persisted for more than 1 year (Stearns and others, 2008). Some studies of active lakes (Gray and others, 2005; Wingham and others, 2006) have found closed or partially closed lake-water systems, in which discharge from one lake fills other lakes downstream, while others (Stearns and others, 2008; Fricker and Scambos, 2009) have found lakewater systems that exchange water both between lakes and with the surrounding subglacial environment. The latter behavior allows the greatest potential for lakes to induce rapid changes in ice flow because lakes may add water to, or remove water from, the distributed water systems at the icebed interface that lubricate ice flow.

Although some (27) of the RES-identified lakes are located near or within enhanced flow features (Siegert and Bamber, 2000; Bell and others, 2007; Carter and others, 2007), all are located upstream of outlet glaciers, and water draining from any of these lakes could lead to increased discharge from the continent into the ocean. The RES surveys that detected these lakes have not yet provided evidence to suggest whether they commonly drain and fill at annual to decadal timescales, as do the lakes on the Siple Coast, or whether they are a static part of the basal water system, with volume fluctuations detectable only over much longer timescales.

In this paper, we present the first comprehensive study of active lakes for the Antarctic ice sheet north of $86^{\circ} \mathrm{S}$, based on 4.5 years (October 2003-March 2008) of ICESat laser altimeter data. We analyze the full ICESat dataset over the Antarctic ice sheet to detect active subglacial lakes that are evolving at sub-decadal timescales and to estimate volume changes for each lake. These elevation changes are distinguished from other glacier-dynamic elevation changes by their small $(2-10 \mathrm{~km})$ spatial scale and their large $\left(>20 \mathrm{~cm} \mathrm{a}^{-1}\right)$ rates of elevation change relative to the surrounding ice. Although the track spacing of ICESat's data precludes detailed analysis of some coastal fast-flow areas, our study provides the most comprehensive picture to date of active lake systems in Antarctica. It also provides some of the first information on the activity of the RES-detected lakes, and describes the water exchange rates between lake systems and their surroundings.

\section{SURFACE ELEVATION DATA AND DATA CULLING}

The surface elevation data used for this study come from the Geoscience Laser Altimeter System (GLAS) aboard NASA's ICESat. Processed ICESat data provide surface elevation profiles along ground tracks that repeatedly survey the same set of reference tracks two to three times per year, giving elevations for 30-70 m footprints every $170 \mathrm{~m}$ along track, with a spacing between adjacent reference tracks of $\sim 30 \mathrm{~km}$ in the northernmost parts of Antarctica to near zero at the $86^{\circ} \mathrm{S}$ turning latitude. The reference tracks are repeated with an accuracy of $\sim 150 \mathrm{~m}$, and the horizontal location of the ICESat footprints is estimated with an accuracy of $\sim 10 \mathrm{~m}$. Over ice sheets, ICESat data are provided as GLA12 records (H.J. Zwally and others, http://nsidc.org/data/gla12.html), which include the latitude, longitude and elevation of each geolocated footprint, as well as a set of parameters that describe characteristics of the returned pulse and the processing used to derive the elevations. These data were acquired during 13 separate campaigns, between August 2003 and March 2008, each lasting approximately 1 month (Table 1). Low transmitted laser power degraded the data for the June 2004 (2c) campaign, and those data are not used in this study.

ICESat data need to be culled to remove surface-return data that are acquired when clouds are present between the satellite and the surface, because these reduce the accuracy of the derived surface elevations. Various methods have been adopted to do this, including a simple gain/energy filter (Fricker and Padman, 2006) and the introduction of a multiple scattering warning flag in the GLA12 records. We have developed an algorithm that culls the data based on the return waveform characteristics to remove cloudaffected data and to reduce the scatter in surface returns (Smith and others, 2005). We use two main parameters as criteria to assess data quality: (1) the apparent surface reflectivity, and (2) the misfit between the received waveform and the Gaussian model fit to the waveform that is used by the ICESat processing algorithm to estimate the surface elevation. Our requirement is that the apparent reflectivity is $>0.1$, and the waveform misfit is $<0.035 \mathrm{~V}$. This gives a median absolute crossover difference of $0.05 \mathrm{~m}$ for flat surfaces, while retaining about $85 \%$ of all returns. Under the assumption that the individual shot errors are Gaussian-distributed, this implies a single-shot accuracy of $\sim 0.075 \mathrm{~m}$ for flat surfaces. For slopes greater than about $0.3^{\circ}$, the crossover errors increase approximately linearly with the magnitude of the surface slope, reaching $0.2 \mathrm{~m}$ for $1^{\circ}$ slopes. As a result, because surface slopes on the Antarctic ice sheet are generally $<0.5^{\circ}$, we expect that most errors are $<0.1 \mathrm{~m}$. Because cloud conditions are spatially correlated, data tend to be culled for long segments of a repeat pass, rather than one shot at a time. After data culling, for a given location on a reference track, up to 12 repeat measurements may be available.

\section{METHODS}

In this section, we describe how we derive lake volume changes from ICESat elevation data. We first estimate the elevation changes on the ICESat tracks, then interpolate the elevation changes between the tracks to derive a volume change estimate. 


\subsection{Estimation of elevation change}

After data culling, we divide each ICESat reference track into overlapping short $(700 \mathrm{~m})$ segments whose centers are separated by $500 \mathrm{~m}$ along-track, and we accumulate all the valid repeat data for each segment, which results in a rectangular strip $700 \mathrm{~m}$ along-track by $\sim 300 \mathrm{~m}$ across-track. For each strip, we estimate temporal patterns of elevation change by calculating the residuals to the plane that best fits the data. We simultaneously solve for the static component of the surface slope and the secular rate of elevation change. For each strip we fit the elevations, $\mathbf{z}$, shot times, $\mathbf{t}$, and return locations, $\mathbf{x}$ and $\mathbf{y}$, with a planar model, $z_{\mathrm{p}}$ :

$$
\mathbf{z}_{\mathrm{p}}=([\mathbf{x}, \mathbf{y}]-\langle[\boldsymbol{x}, \mathbf{y}]\rangle)^{T} \mathbf{m}+\left(\mathbf{t}-t_{0}\right)\left(\frac{\partial z}{\partial t}\right)+\langle\mathbf{z}\rangle
$$

Here $\mathbf{m}$ gives the estimated surface-slope vector, $\langle[\mathbf{x}, \mathbf{y}]\rangle$ is the mean of the footprint locations, $\langle\mathbf{z}\rangle$ is the mean surface elevation, $\mathbf{t}_{0}$ is a time close to the middle of the ICESat mission (1 December 2005) and $\partial z / \partial t$ gives the secular rate of elevation change.

The residuals to this planar model, $\mathbf{r}=\mathbf{z}-\mathbf{z}_{\mathrm{p}}$, give footprint elevations corrected for the repeat-track separation, the static component of the surface slope, and the mean rate of elevation change. The elevation-change values for each pass, for each segment, are given by

$$
\mathrm{d} \mathbf{z}=\mathbf{z}-\mathbf{z}_{\mathrm{p}}+\left(\mathbf{t}-t_{0}\right) \frac{\partial z}{\partial t}
$$

Under this procedure, the slope estimates from Equation (1) have been corrected for the mean rate of elevation change, which is usually the largest component of elevation change, and otherwise would lead to errors in the slope estimate. The second term in Equation (2) adds the secular elevation change to the residuals to give the total elevation change.

We found that this algorithm performs well in separating cross-track slope effects from true elevation change when there are at least six repeats of a given reference track. Consequently, we do not use tracks for which fewer than six repeats are available.

\subsection{Identification of active lakes from elevation anomalies}

We identify regions of large elevation-change anomaly by mapping the total range of $\mathrm{d} \mathbf{z}$ for all ground tracks across Antarctica. For most parts of the ice sheet, $\mathrm{d} z \mathbf{z}$ values have a range $0.05-0.1 \mathrm{~m}$, mostly due to ICESat instrumental errors. In most cases on grounded ice where the range is larger than this, the anomaly may be explained by six common causes:

1. In regions with rugged subglacial topography and in the dynamic topography associated with active ice streams, elevation errors may result from cross-track errors caused by large surface slopes, and from uncertainties in the geolocation of the ICESat footprints;

2. In crevassed regions, ICESat's 50-70 m footprint may sample both sagging snow bridges and wind-blown surface snow accumulating near crevasse openings, producing short-scale spatial scatter in elevation measurements. Both under-sampling of these variations and the advection of crevasses by ice motion may produce large local apparent elevation change;

3. In a few regions experiencing large rates of secular mass imbalance, notably the Kamb Ice Stream catchment and the Pine Island and Thwaites Glacier catchments, the elevation-change values show a large linear trend in time (Shepherd and Wingham, 2007);

4. In regions where there are large temporal variations in ice speed or basal friction, the dynamic topography on the surface can change even though the bed elevation is constant. In both cases, the predicted surface changes have a characteristic dipole shape, with local surface depression adjacent to local uplift (Gudmundsson, 2003; Sergienko and others, 2007);

5. On ice shelves, tidal displacements produce elevation changes with amplitudes of up to several meters near grounding lines (Fricker and Padman, 2006);

6. In a few cases, the data-culling process leaves some returns that have been strongly affected by forward scattering of laser light through clouds, producing anomalously low elevations.

For each region where elevation-change anomalies were observed, we considered whether they could be attributed to the six common causes above. If all could be ruled out, we interpreted the signals as due to 'active lakes', subglacial bodies of water either gaining or losing water (or both) over the ICESat observation period (Gray and others, 2005; Fricker and others, 2007). As an example, we show elevation ranges for Academy Glacier (Fig. 2; location shown in Fig. 1 (key in Table 2)) and its upstream tributary region. This glacier enters Foundation Ice Stream, which then joins the Filchner Ice Shelf in West Antarctica. Large tidal displacements (cause 5) are visible on the ice shelf (dashed orange outline), and large apparent displacements (cause 1) are common where the surface slope exceeds about $1^{\circ}$ (dashed green outline). In addition, there are 16 areas that show elevation ranges of 1-6 m (magenta outlines). Because they are not associated with surface slopes, tides or any of the other effects on the list above, we identify these as active lakes.

For a region to be identified as an active lake, we adopt three criteria for its pattern of elevation-change anomaly. First, it must not easily be explainable by instrumental errors. This requires that the temporal pattern of elevation change be smooth, to be distinguished from instrumental noise. This implies that the ability to detect active lakes in cloudy coastal regions (e.g. the Amundsen Coast) is limited. Second, the anomaly must not be correlated with the temporal pattern of the across-track displacements of the repeat tracks. This implies that active lakes cannot be identified in tracks that have poor repeat-track geometry, such as when the tracks are acquired in a spatially progressive order (e.g. from left to right across the reference track). The final criterion is that an active lake must be measured on at least two different reference tracks, and the pattern of elevation change must be the same for each track. We classify lakes that are only identified on one track as 'provisionally active' lakes.

\subsection{Estimation of lake volume change}

ICESat-detected elevation-change anomalies across lakes have a smooth spatial variation along each ground track at each epoch. We therefore assume that a smooth spatial interpolant will produce a good estimate of the pattern of surface displacements for each lake, allowing us to combine multiple tracks crossing a lake to estimate the total volume displaced. To construct this interpolant for each anomalous region, we define a bounding polygon that encompasses all 


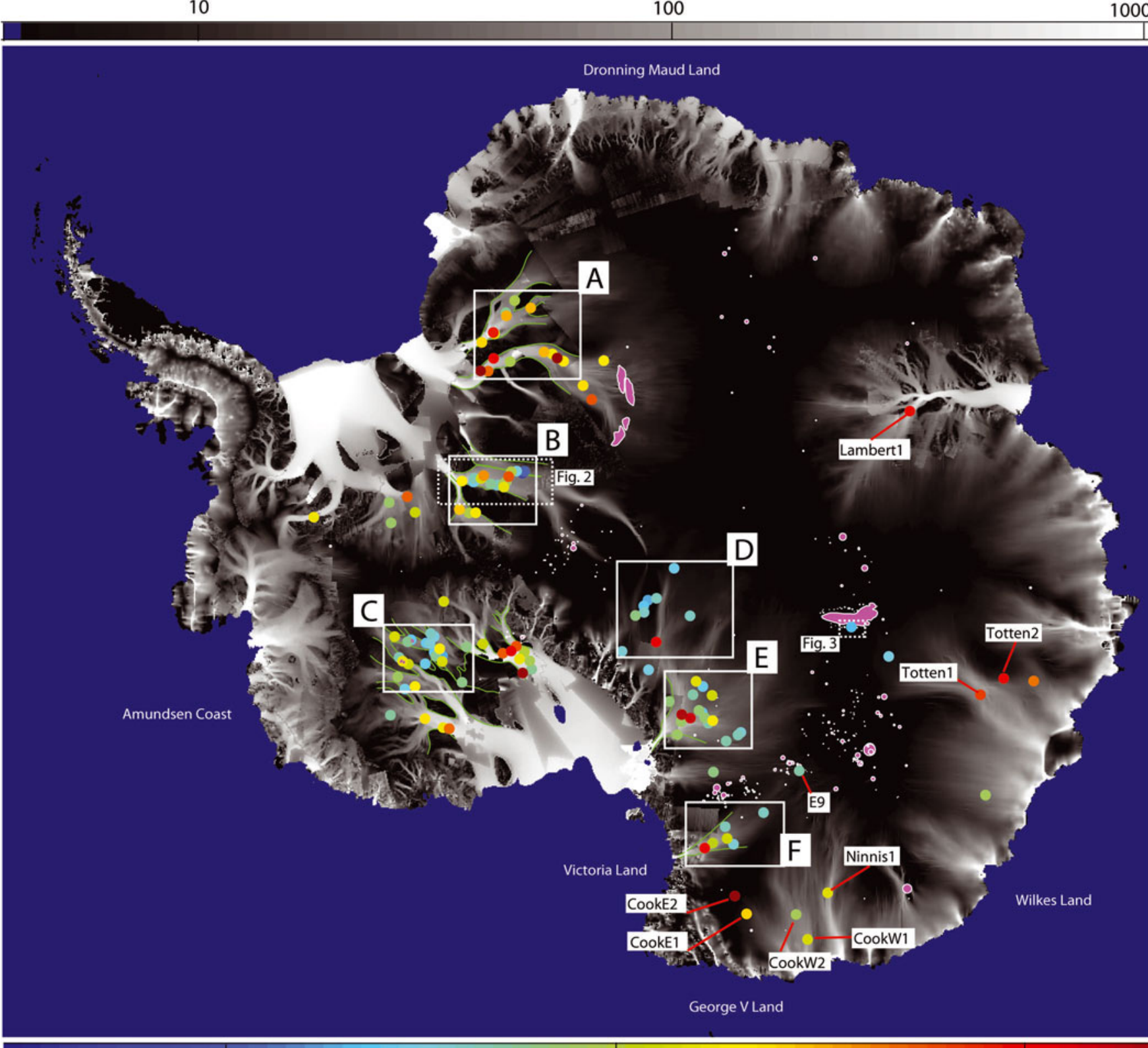

0.01

Fig. 1. Locations and volume-range estimates for 124 active lakes under the Antarctic ice sheet found in this study, shown as points colorcoded by the volume range. Background shading shows a combination of satellite-radar-derived surface velocities (Joughin and others, 1999, 2006) and balance velocities (Bamber and others, 2008). White outlines filled in magenta represent previously published lake locations: outlines are drawn for Vostok Subglacial Lake (Studinger and others, 2003), the Recovery Glacier lakes (Bell and others, 2007) and active lakes mapped with radar altimetry in Adventure Trench (Wingham and others, 2006) and with interferometric synthetic aperture radar (InSAR) on Kamb Ice Stream (Gray and others, 2005). Lakes mapped from airborne radar are represented by circles of diameter equal to the published lake length (Siegert and others, 2005; Carter and others, 2007; Popov and Masolov, 2007). Green curves show approximate extent of streaming and tributary flow for selected glaciers; boxes correspond to insets in Figure 4. Regional lakes are labeled sequentially for identification in Figures 7-13. Locations for Figures 2 and 3 are shown by dotted outlines.

elevation-change anomalies greater than about $0.1 \mathrm{~m}$ found on all tracks across the lake. For all track segments within the bounding polygon, we construct a complete set of elevationchange values. For each track segment, we define a corrected elevation-change anomaly for each campaign as:

$$
\mathrm{d} z_{\mathrm{c}}(x, y, T, c)=\mathrm{d} z(x, y, T, c)-\mathrm{d} z_{0}(T, c) .
$$

Here $d z_{0}$ gives the background elevation-change value for each reference track, $T$, for each campaign, $c$, defined as the median of the elevation-change values for all points outside the bounding polygon, but within $5 \mathrm{~km}$ of the lake boundary. This correction allows us to estimate water volume change in areas where the surface is changing rapidly due to ice-flux divergence (e.g. in the Kamb Ice Stream catchment), under the assumption that elevations within the polygon are changing due both to ice-flux divergence and to water motion, while elevations outside the polygon are changing only due to ice-flux divergence. 

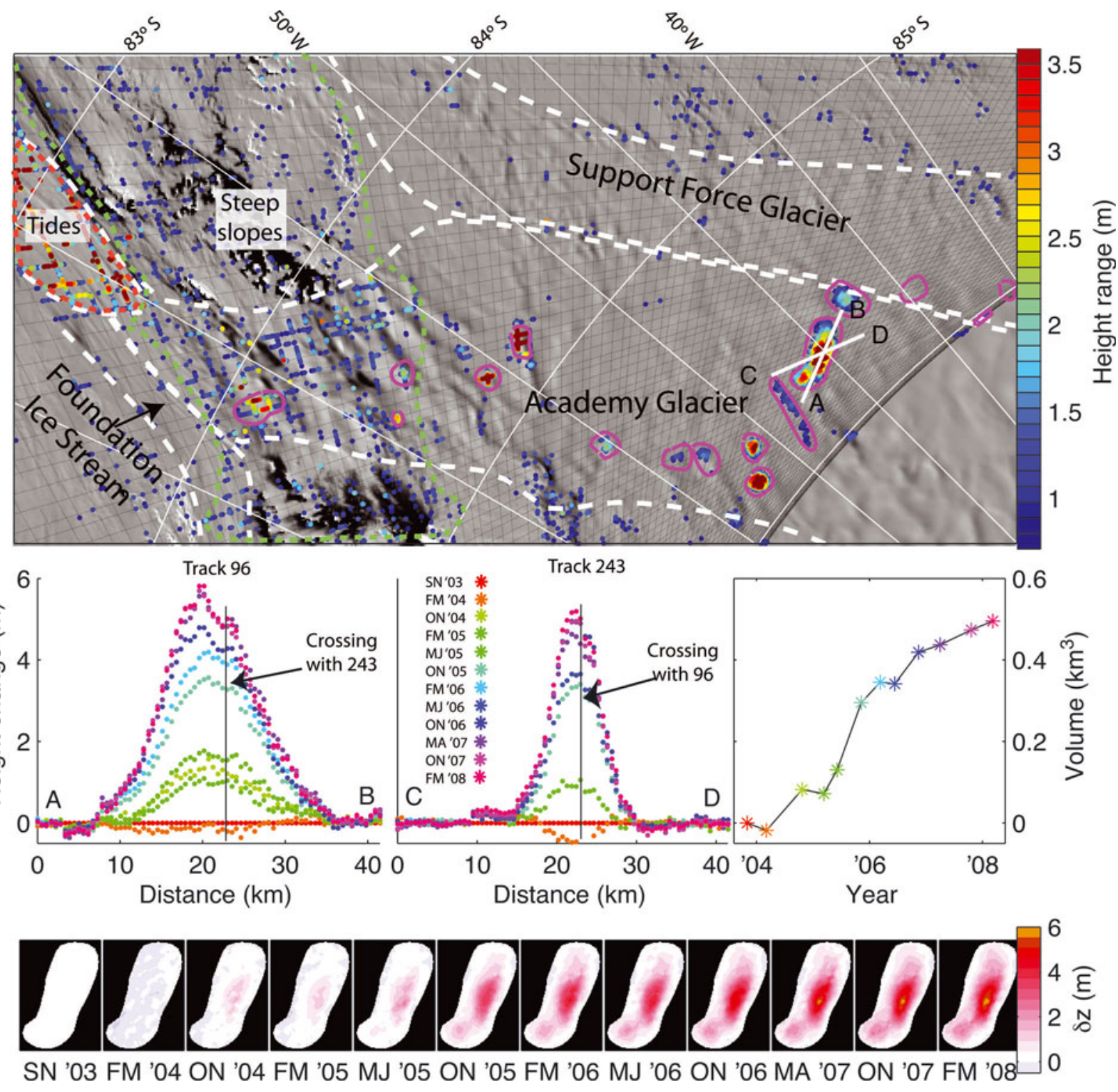

Fig. 2. Top: ICESat tracks over the catchment of Academy Glacier. ICESat tracks for which six or more valid repeats were found are shown in black, and tracks for which the total elevation range for all valid repeat passes exceeds $0.5 \mathrm{~m}$ are color-coded by the elevation range (color scale at right). Inferred lake boundaries are shown in magenta, ice-stream catchment boundaries are shown by dashed white curves and the area of relatively large surface slopes, over which ICESat elevation errors are expected to produce large residuals, is shown by a dashed green outline. Floating ice, where tidal displacements produce large displacements, are shown by a dashed orange outline. Background image is the MODIS (moderate-resolution imaging spectroradiometer) Mosaic of Antarctica (Scambos and others, 2007). Middle left and center: elevation displacements relative to the October-November 2003 campaign for two ICESat tracks (see AB and CD in top plot for location; $A B$ is track 96, CD is track 243) across a filling lake in the upper Academy Glacier catchment. Colors of points correspond to the time of each profile, as shown at center. Middle right: Estimated volume history for this lake relative to the October-November 2003 campaign. Bottom: Sequential gridded displacement estimates for 12 ICESat campaigns, color code given at right. The letters at the bottom of each plot give the months and years of the campaigns.

When data culling leaves gaps in the time series (i.e. missing campaigns) for a track segment, we fill in the missing values with the linear regression of the mean value within the polygon as a function campaign number, $\langle\mathrm{d} z\rangle(c)$, on the elevation series for that point, $\mathrm{d} z(x, y, c)$. Because elevation changes for all points above any lake are usually in phase, this process produces elevation-change anomaly estimates that are smooth in both space and time. If fewer than half of the segments within the outline have valid data during a campaign, however, no surface estimate is generated for that campaign, leaving a gap in the timevolume history for that lake. For purposes of determining volume changes in this way, all elevation anomaly measure- ments from the same campaign are treated as if they took place at the same time, even through in reality the acquisition times may be up to 33 days apart.

We then select a gridded surface displacement estimate for each campaign, $S(x, y, c)$, that minimizes a weighted misfit:

$$
\begin{aligned}
& \mathrm{E}(c)=\sum_{\text {datapoints }}\left[S(x, y, c)-\mathrm{d} z_{\mathrm{c}}(x, y, c)\right]^{2} \\
& +\sum_{\text {boundarypoints }} S(x, y, c)^{2}+\lambda^{2} \sum_{\text {gridpoints }}\left[\nabla^{2} S(x, y, c)\right]^{2} .
\end{aligned}
$$

The first term minimizes the misfit between the displacement estimate and the data points, the second term 
Table 2. Abbreviations used in Figures 1 and 4

\begin{tabular}{lcc}
\hline Inset & Region name & Abbreviation \\
\hline A & Slessor Glacier & $\mathrm{S}$ \\
& Recovery Glacier & $\mathrm{R}$ \\
$\mathrm{B}$ & Academy Glacier & $\mathrm{A}$ \\
& Foundation Ice Stream & $\mathrm{F}$ \\
$\mathrm{C}$ & Kamb Ice Stream & $\mathrm{K}$ \\
& Kamb trunk & $\mathrm{KT}$ \\
& Raymond Ridge & $\mathrm{RR}$ \\
$\mathrm{D}$ & Bindschadler Ice Stream & $\mathrm{B}$ \\
& East Antarctic plateau & $\mathrm{E}$ \\
& Lennox-King Glacier & $\mathrm{L}$ \\
$\mathrm{E}$ & Nimrod Glacier & $\mathrm{N}$ \\
& Byrd Glacier (large lakes) & $\mathrm{By}$ \\
$\mathrm{F}$ & Byrd Glacier (small lakes) & $\mathrm{Bs}$ \\
& David Glacier & $\mathrm{D}$ \\
\hline
\end{tabular}

constrains the displacement estimate to be close to zero on the bounding polygon, and the third term minimizes the curvature of the displacement estimate. A Lagrange multiplier, $\lambda$, determines the relative importance of the smoothness constraint and the misfit in determining the shape of the surface. A good choice of $\lambda$ produces a data misfit approximately equal to the errors in the data. Although the optimal $\lambda$ depends on the track geometry and the grid spacing, we have found that selecting $\lambda=n_{\text {data }} / n_{\text {grid }}$ where $n_{\text {data }}$ is the number of track segments and $n_{\text {grid }}$ is the number of gridpoints, gives appropriate misfit values in most cases. This procedure may, for some track geometries, produce surfaces whose maxima or minima are located between reference tracks, which might produce spuriously large volume displacement estimates. To avoid this, we truncate the surface displacement estimate for each campaign at the maximum and the minimum of $\mathrm{d} z_{\mathrm{C}}$ for that campaign, at the cost of a bias towards smaller volume estimates.

The volume displacement for each valid campaign calculated from our gridded displacement estimates is

$$
V(c)=\int_{b} S(x, y, c) \mathrm{d} A
$$

where the integral is calculated within the bounding polygon. Only the relative volume displacement between two campaigns is meaningful, because the elevation-change anomaly values are constructed to have an average value of zero at 1 December 2005. Because we expect surfaceelevation changes due to bed-elevation changes to be smooth on a spatial scale of about three times the ice thicknesses (Gudmundsson, 2003), we assume that a spatial sampling of one point every three ice thicknesses is sufficient to characterize the elevation change field. We describe the extent to which the ICESat track geometry falls short of this condition by the 'constraint ratio', the fraction of the area within each bounding polygon that falls within 1.5 ice thicknesses of a measurement point.

To estimate the errors in our volume-change estimates, we assume that the ICESat measurement errors are correlated for each pass, and that each measurement has a raw elevation error of $0.1 \mathrm{~m}$. For a typical lake, with an area of $150 \mathrm{~km}^{3}$ (corresponding to the median of the lakes we detected), crossed by three tracks, the error in the volume difference between any two campaigns is $0.012 \mathrm{~km}^{3}$ or about $13 \%$ of the median volume range of $0.09 \mathrm{~km}^{3}$. This error is small compared to the interpolation error caused by the large gaps between tracks: The median number of tracks per lake for the confidently identified lakes is three, so the interpolation needed to derive the volume-displacement estimate is based on sparse data. While there is no simple way to assign a magnitude to this error, it does not seem unreasonable to estimate that the scale of the volume differences for any given lake could be incorrect by $50 \%$, either because the spatial extent of the elevation-change anomaly was not accurately determined, or because the tracks did not adequately sample the spatial variations in the elevation change anomaly. This error is most likely to be in the absolute scale of the displacement estimates, because for each campaign the gridding process should produce a consistent ratio between the displacement magnitudes on the tracks and the volume displacement estimate, the magnitude of this ratio being determined by the track geometry.

\subsection{Interpretation of volume changes}

The interpretation of small-scale surface displacement to recover subglacial water movement is complicated by the fact that other subglacial processes can also result in surface deformation. This opens up the possibility that the surface elevation-change signals observed in ICESat are not solely due to subglacial water activity. Indeed, ice-flow models show that local changes both in basal friction and in basal topography can produce changes in surface elevation (Gudmundsson, 2003). Although the modeled dipole shape of the surface expression of a local increase in basal shear stress is quite different from the surface expression of a local rise in basal topography (Gudmundsson, 2003; Sergienko and others, 2007), when sampled by only one or two ICESat tracks, either shape could easily be misinterpreted as the surface expression associated with a subglacial lake. This is a limitation of the dataset that we cannot entirely avoid, and some skepticism is appropriate in interpreting results based on lakes that we have identified based on only one or two tracks.

Fricker and others (2007) assumed that the volume of ice displaced at the surface equals the volume of water displaced at the bed. Detailed modeling of a lake drainage beneath the center of a fast-flowing ice stream (Sergienko and others, 2007), however, showed that ice motion during and after the lake drainage can result in surface displacements as much as $60 \%$ smaller than the corresponding icesole displacement, and that surface motion continues for some years after the end of water movements at the bed. Their conclusion was that observed surface-volume change is a poor proxy for the volume of water displaced at the bed. This study, however, modeled flow for only a limited set of cases, and the character of their initial displacements differs substantially from those observed. Measured surface displacements are significantly gentler than the steep-sided depressions used in their model, so the diffusion of actual features due to ice flow should be far more moderate than that modeled. Furthermore, subglacial lakes appear to fill and drain over relatively short intervals, which further limits the influence of ice flow in volume estimates. Finally, the degree to which transient perturbations in basal topography and slipperiness express themselves in surface topography 

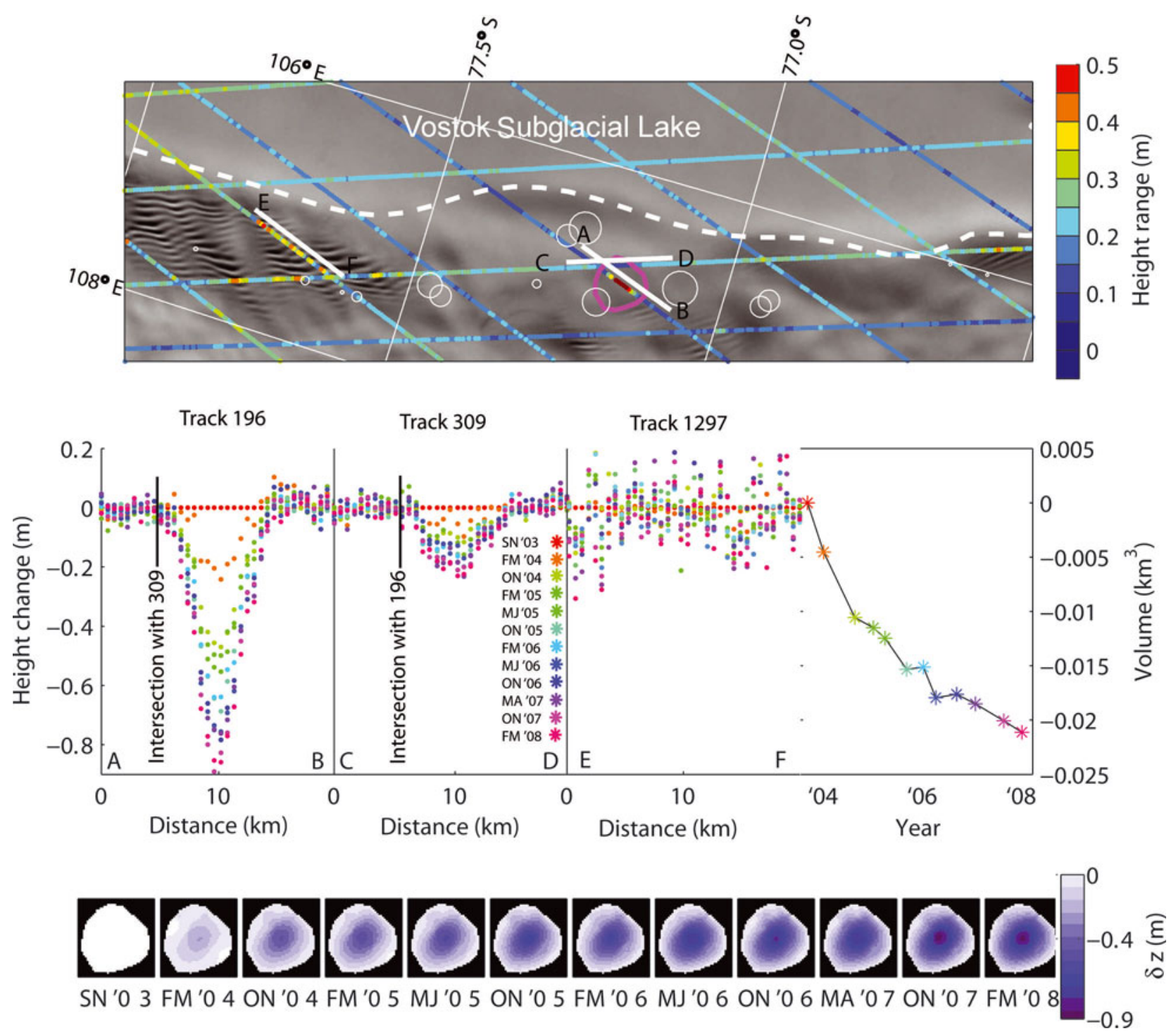

Fig. 3. Top: Elevation displacements at the eastern edge of Vostok Subglacial Lake, overlaid on MODIS Mosaic of Antarctica (Scambos and others, 2007). The magenta outline shows the inferred boundary of an active lake; the dotted outline shows the perimeter of Vostok Subglacial Lake (Studinger and others, 2003). Middle row: Elevation displacements along ICESat tracks 196 and 309 (AB and CD in top plot for location), which pass over the active lake, and track 1297 (EF), which does not. Elevations are plotted relative to the October-November 2003 campaign; the colors of the points correspond to the profile times, as shown at center. Middle right: inferred time series of volume displacements for this lake drainage. Bottom: Sequential gridded displacement estimates, relative to October-November 2003 campaign, based on tracks 196 and 309, using the outline shown at top.

depends on the effective ice viscosity, which depends on temperature, ice crystal fabric and strain rates produced by regional ice flow. For these reasons, we continue to use the volume displacements observed at the surface as an indicator of change in water volume at the bed. Nonetheless, we recognize that ice flow may have some influence on the ICESat signals, potentially making the character of our results more qualitative than quantitative.

\section{RESULTS AND DISCUSSION}

Over the entire Antarctic ice sheet, we identified a total of 108 active lakes, and an additional 16 provisionally active lakes that were only detected on a single track (Fig. 1). In this section, we detail the analysis of two lakes, then describe the spatial distributions of all the lakes, the temporal patterns of water motion into and out of the lakes, and the implications for lake and ice-sheet dynamics.

\subsection{Selected results for two areas of different spatial sampling}

We present results of our entire procedure, from elevationchange anomaly mapping to interpolated elevation changes to volume estimation, for two regions that we selected based on their spatial sampling by ICESat. The first is well sampled spatially (Academy Glacier (Fig. 2; Fig. 1 for location)) and the second is more poorly sampled (near Vostok Subglacial Lake (Fig. 3)). These cases demonstrate the interpretive steps needed to obtain volume change estimates, and demonstrate how spatial sampling can affect our results.

4.1.1. Academy Glacier lakes (dense spatial sampling) ICESat's coverage of Academy Glacier is relatively dense, with a maximum track spacing of $\sim 7 \mathrm{~km}$, and the lakes shown in Figure 2 are sampled by 5-17 tracks each. In the tributary region, we detected a large active lake at $85.7^{\circ} \mathrm{S}$, near the turning latitude of ICESat, which was crossed by 13 
ICESat tracks, with a total of 174 independent valid repeat passes. We show elevation changes along two intersecting tracks (tracks 96 and 243). The elevations are increasing with time, which we interpret as surface uplift in response to filling of the lake. Elevation changes vary smoothly on spatial scales of $4-6 \mathrm{~km}$, reaching maximum values of $\sim 5-$ $6 \mathrm{~m}$. The temporal pattern of displacements for each track shows a steady increase in elevation between February 2004 and March 2008, and both tracks show approximately the same elevations for each campaign at their intersection point. Except for two lakes on Whillans Ice Stream (Fricker and Scambos, 2009, their figs $2 \mathrm{a}$ and $3 \mathrm{~b}$ ), where the ice is thin $(<1 \mathrm{~km})$ compared to the lake length $(\sim 30 \mathrm{~km})$, the smooth 'Gaussian-like' spatial pattern of displacements seen here is typical of all the active lakes we detected, with displacements showing a distinct maximum and then tapering to zero at the edge of the lake over a distance of a few times the ice thickness.

Figure 2 (bottom) shows the interpolated elevation changes for the Academy Glacier lake. There is close agreement between elevation-change values detected on different tracks, as can be seen in the smoothness of the gridded elevation values. The largest uplift is towards the southeastern side of the lake, and measurable uplifts are distributed over an area of $207 \mathrm{~km}^{2}$. The peak elevation values relative to the first campaign were -0.26 and $5.9 \mathrm{~m}$, although because the peak uplift was confined to a small region, the largest mean displacements within the bounding polygon are much smaller, at -0.06 and $1.4 \mathrm{~m}$. A plot of the volume displacements against time (middle right) shows that the lake filled steadily between October 2003 and March 2008, with a mean displacement rate of $0.13 \mathrm{~km}^{3} \mathrm{a}^{-1}$.

\subsubsection{Small lake near Vostok Subglacial Lake (coarse spatial sampling)}

In contrast, Figure 3 shows the procedure for a small lake in East Antarctica, at $77^{\circ} \mathrm{S}$, which was sampled by only two ICESat tracks. For this lake, the boundary was poorly defined by the elevation-change anomalies detected on the ground tracks, so the volume estimates are not as well constrained as for the Academy Glacier lake. The large elevation changes measured on track 196, the small elevation changes measured on track 309 and the lack of significant elevation changes on adjacent tracks suggest a lake boundary centered on track 196, and the simplest shape for this boundary is a circle, with an area of $67 \mathrm{~km}^{2}$. Our gridding algorithm gives a volume range of $0.02 \mathrm{~km}^{3}$. Because the tracks sample the lake so poorly, we do not know whether this is an overestimate or an underestimate of the lake volume displacement. It is possible that the true shape of the lake was elongated parallel to track 196, and that we have overestimated its area, but because measurable displacements extend as far as track 309, it seems likely that the lake is elongated perpendicular to track 196, and the circular boundary underestimates its area. For simplicity, we retain the circular boundary.

To demonstrate the difference in character between elevation-change anomalies that arises from lake displacements and those due to instrumental errors, we also show a profile of elevation changes across a region of high surface roughness (profile EF, track 1297) where the elevationchange anomalies show large scatter, but no coherent pattern as a function of space and time.

\subsection{Distribution of active lakes}

Figure 1 shows the locations of the active lakes found in Antarctica, as well as the locations of RES-located lakes, all superimposed on a map of the ice surface speed. Each active lake is represented by a dot, color-coded by the range in volume for that lake. Table 3 summarizes the 31 largest lakes, all of which had volume ranges greater than $0.2 \mathrm{~km}^{3}$. These lakes make up more than $80 \%$ of the cumulative volume displacement for the entire set of 124 active and provisionally active lakes. The distribution of lake-volume changes is such that the cumulative volume change due to the largest lakes is much larger than that of the smallest. The largest volume change was from a lake in George $\mathrm{V}$ Land, East Antarctica, which drained $2.7 \mathrm{~km}^{3}$, a rate of $2.1 \mathrm{~km}^{3} \mathrm{a}^{-1}$ $\left(68 \mathrm{~m}^{3} \mathrm{~s}^{-1}\right)$ between November 2006 and March 2008. The next largest lakes (by volume range) were on Byrd Glacier, East Antarctica, where lake Byrd $_{2}$ inflated by $1.4 \mathrm{~km}^{3}$ between October 2003 and May 2006, and on Recovery Glacier, West Antarctica, where a lake drained by $2.2 \mathrm{~km}^{3}$ between November 2002 and February 2008. The Byrd Glacier subglacial flood caused a $10 \%$ speed-up of the main glacier trunk that lasted for 14 months (Stearns and others, 2008). The remaining lakes are included in Figures 1 and 46 , and are described in the Appendix (Table 4).

With a few exceptions, active lakes are located in regions of fast ice flow, either in ice-stream outlet or in the tributary regions feeding them (Fig. 1). Ice velocities are well constrained by satellite synthetic aperture radar (SAR) measurements in the Siple Coast region and in the Filchner Ice Shelf drainage (Joughin and others, 1999, 2006). In these regions, all observed lakes are within ice-stream or tributary regions (Figs 1 and 4). The association between ice velocity and lake locations is less clear in Victoria Land, George V Land and Wilkes Land, because the ice velocity in these regions is not well known. Most lakes, however, are clustered within $200 \mathrm{~km}$ of major outlet glaciers, in areas where balance-velocity maps (Bamber and others, 2008) suggest that there may be enhanced ice flow comparable to the tributary regions of West Antarctica. This pattern probably reflects the melting basal conditions common beneath fast-flowing ice (Bentley and others, 1998; Studinger and others, 2001), which supplies water to refill drained lakes and allows more efficient water transport than would freezing basal conditions.

On theoretical grounds, Bindschadler and Choi (2007) predicted that lakes should be concentrated in ice-stream tributaries because the ice surface texture created by bed roughness in the tributary region often creates pockets in the basal hydrologic potential that can trap water. A second prediction was that in ice-stream trunks, the higher sliding velocity produces surface topography that creates fewer, shallower pockets, and thus traps less water. The latter prediction is not well supported by our observations, as lakes are common in some ice-stream trunks as well. Because lakes are small, with typical widths less than $20 \mathrm{~km}$, and are found in areas with relatively strong surface texture (i.e. surface undulations on horizontal scales of $10 \mathrm{~km}$ or less), there is rarely an identifiable surface elevation signature marking the lake location. This is in contrast to Vostok Subglacial Lake and to the lakes at the head of Recovery Glacier (Bell and others, 2007), probably because of the small size of the active lakes. Only a few of the lakes with the largest areas (e.g. the lake profiled in Fig. 2) are marked by flat surfaces that imply that the ice is in 
Table 3. Parameters for the 31 largest-displacement lakes. Columns give (1) subglacial lake names corresponding to the glacier or area in which the lakes are found, numbered by distance from the grounding line; (2) the number of ICESat tracks used to derive the volume-change estimates; (3) the constraint ratio (equal to the fraction of the area within the bounding polygon that is less than 1.5 times the ice thickness from the nearest track); (4) the surface velocity from interferometric synthetic aperture radar (InSAR) where known (Joughin and others, 1999), or otherwise based on balance velocity (Bamber and others, 2008) (balance velocities are given in square brackets); (5) ice thickness, $H$, from the BEDMAP database (Lythe and others, 2001); (6) month and year (+2000) for start and end times of each interval of drainage or filling; and (7) volume displacements for each interval, in $\mathrm{km}^{3}$

\begin{tabular}{llllll}
\hline Lake name $\quad$ \# tracks & $R_{\text {constraint }}$ & $|V|$ & $H$ & Start & End \\
& $\mathrm{m} \mathrm{a}^{-1}$ & $\mathrm{~m}$ & $\delta V$ & $\mathrm{~km}^{3}$
\end{tabular}

(1)

(2)

(3)

(4)

(5)

(6)

(7)

Academy $_{5}$
Academy $_{12}$
Byrd $_{1}$

1.0

100

60

2077

2799

3

0.8

82.6

2024

Byrd $_{2}$

0.6

[157]

2145

Cook $_{\mathrm{E} 1}$

0.5

Cook $_{\mathrm{E} 2}$

0.9

0.4

0.8

Foundation $_{1}$

0.8

0.5

Lambert $_{1}$

MacAyeal $_{1}$

0.5

0.7

[9]

[2]

112

2746
2690

1779

1067

[89]

1852

2145

313

455

982

MacAyeal $_{3}$

2

266

1154

Mercer $_{2}$

6

0.9

328

1133

Nimrod $_{2}$

Recovery ${ }_{1}$

Recovery $_{2}$

Recovery $_{3}$

1.0

35.3

268

273

0.4

220

Recovery 5

0.8

153

104

[45]

[43]

Recovery ${ }_{9}$

Recovery $_{10}$

0.9

1.0

1.0

Slessor $_{1}$

0.2

445

2841

620

735

501

$10 / 03$
$11 / 03$
$11 / 03$
$3 / 04$

$3 / 08$

0.35

0.5

$3 / 04-0.25$

\section{6/06}

$3 / 07$

$11 / 03$

$11 / 05$

$6 / 06$

11/06

$11 / 03$

$11 / 05$

10/03

10/03

$11 / 03$

3/05

$11 / 03$

$3 / 04$

$11 / 03$

$11 / 05$

6/06

3/07

$11 / 03$

$11 / 03$

$11 / 03$

$11 / 03$

$10 / 04$

6/05

$11 / 03$

$11 / 06$

2188

2420

2506

$11 / 05$

$10 / 04$

6/05

$11 / 03$

$11 / 05$

$11 / 06$

1658

Slessor $_{2}$

0.7

316

$11 / 03$

10/03

3/05

$\mathrm{Slessor}_{7}$

0.8
0.7

141

1942

68.9

1975

Totten $_{1}$

[17]

$11 / 03$

10/05

[92]

3229

Totten $_{2}$

0.7

$11 / 03$

5/05

$11 / 06$

647

Whillans $_{1}$

8

0.4

314

$11 / 03$

$11 / 05$

$11 / 06$

Whillans $_{4}$

10

0.8

545

909

$11 / 03$

6/06

$10 / 03$

$10 / 04$

$10 / 07$

$11 / 03$

$3 / 07$

1.7

$-0.92$

0.42

1.4

$-1.4$

1

0.22

$-2.7$

1.1

$-0.22$

-0.22
0.48

$-0.81$

$-0.44$

0.3

$-0.13$

0.21

$\begin{array}{lr}11 / 05 & 0.43 \\ 6 / 06 & -0.36\end{array}$

$\begin{array}{lr}11 / 05 & 0.43 \\ 6 / 06 & -0.36\end{array}$

$\begin{array}{lr}6 / 06 & -0.36 \\ 3 / 07 & 0.38\end{array}$

$3 / 08 \quad-0.5$

$3 / 08 \quad 1.1$

$\begin{array}{ll}3 / 08 & 2.2\end{array}$

$10 / 07 \quad 0.45$

$10 / 04 \quad 0.16$

$6 / 05-0.26$

$\begin{array}{ll}6 / 057 & 0.92\end{array}$

$\begin{array}{ll}11 / 06 & 0.28\end{array}$

$3 / 08 \quad-0.15$

$10 / 07 \quad-2.1$

$3 / 08 \quad-0.22$

$3 / 08 \quad-0.49$

$11 / 05-0.23$

$11 / 06$

$3 / 08$

0.042

$-0.032$

$3 / 08$

0.77

0.29

0.28

$3 / 08$

$-0.86$

$10 / 05$

0.42

$-0.58$

$5 / 05$

0.4

$-0.31$

$10 / 07$

-0.31
-1.8

0.15
-0.29

$1 / 05$

$10 / 07$

-0.29
0.75

$-1.1$

0.072

$-0.49$

0.026

Wilkes $_{1}$

2

0.8

[26]

3232

$10 / 04$

$10 / 07$

$2 / 08$

0.41 

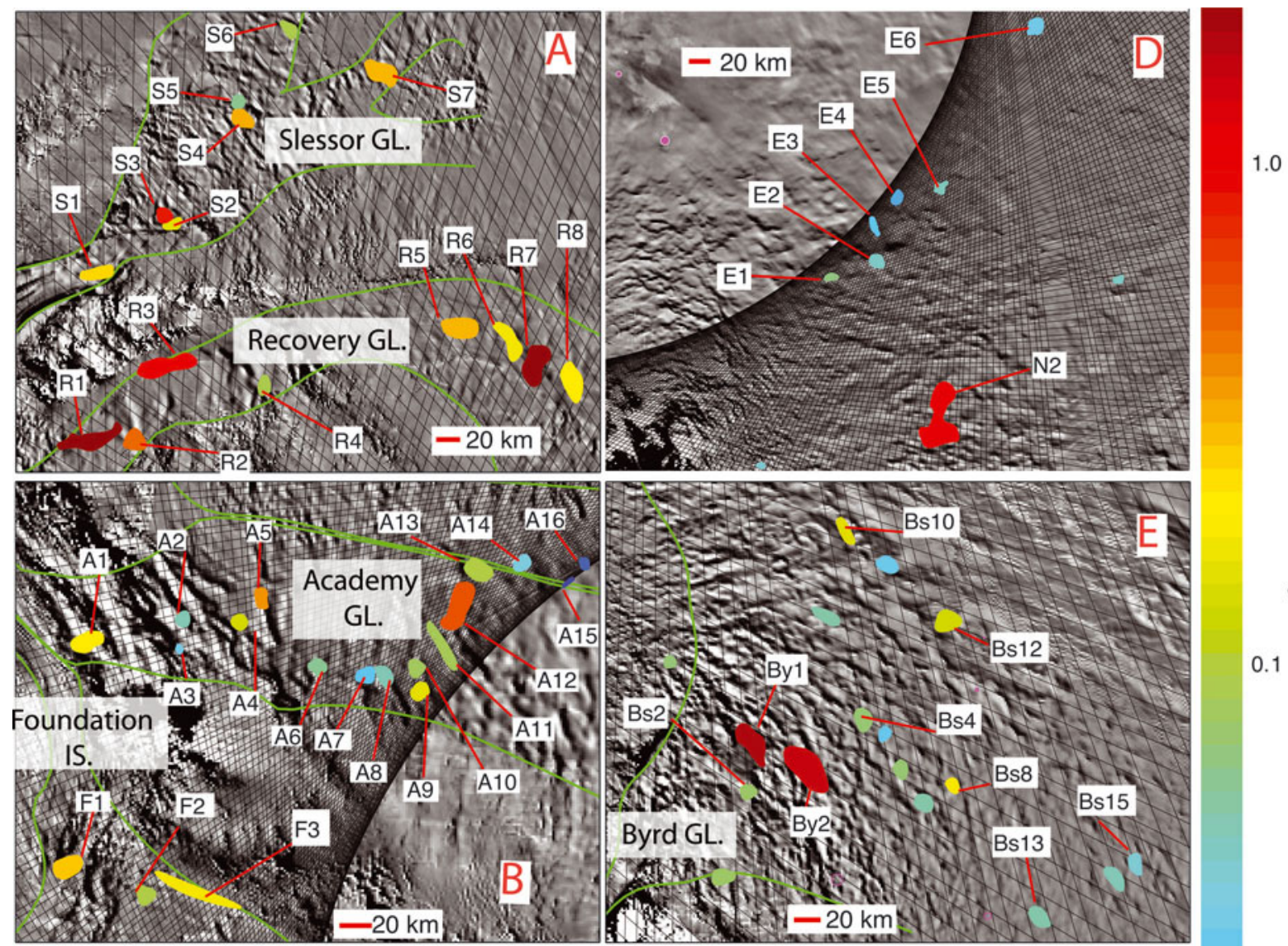

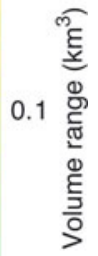
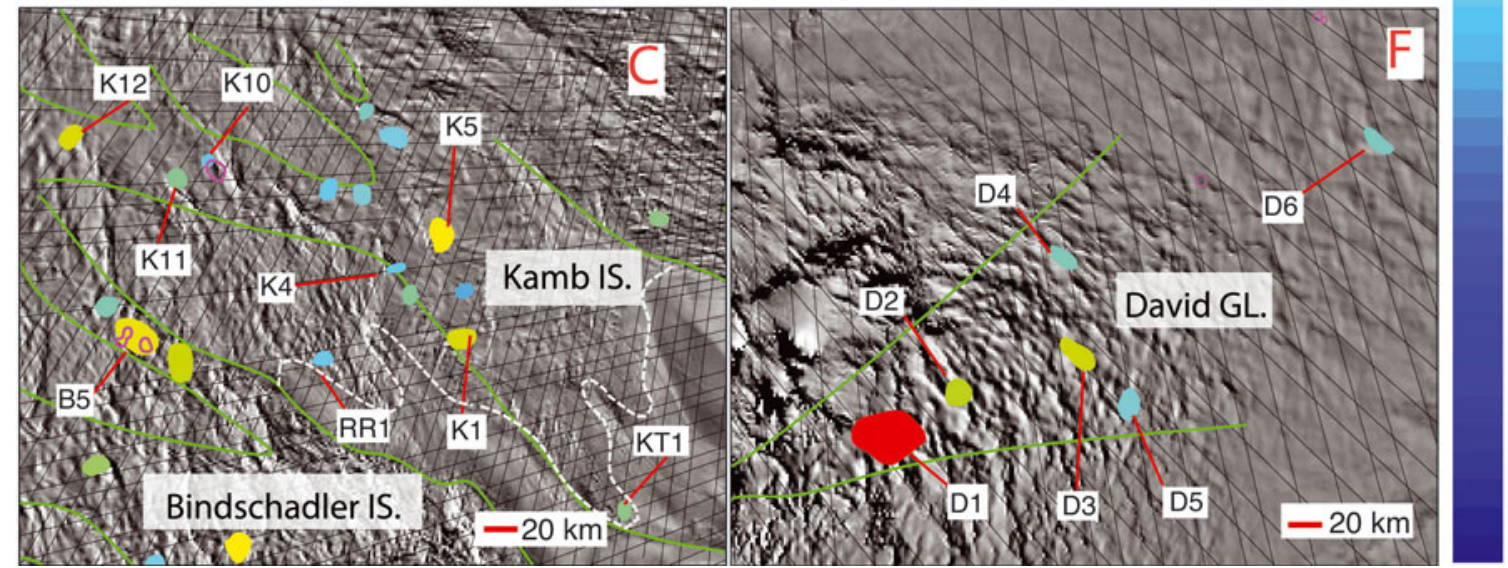

Fig. 4. Locations and volume ranges for selected regions as shown in Figure 1. Lake outlines are color-coded by the lake volume range. Green outlines show the approximate extent of fast-flow and tributary regions as shown in Figure 1. Magenta outlines show previously published lake locations. Regional lakes are labeled sequentially for identification in Figures 7-13; region names are abbreviated as shown in Table 2. Black curves show ICESat tracks for which six or more valid repeats were found. Background grayscale shows the MODIS Mosaic of Antarctica (Scambos and others, 2007). The dotted white curve in inset C shows the approximate downstream extent of fast flow for the Kamb Ice Stream tributary region; green margins downstream of this line show the pre-stagnation margins of Kamb Ice Stream as interpreted from the MODIS Mosaic of Antarctica.

hydrostatic equilibrium with a flat water surface. More typically, they are associated with a variable local surface slope field that includes reversals in surface slope that can trap water. The ICESat and radar altimetry data available for the area either do not or cannot (because of inadequate surface resolution) show a clear surface topographic signature for these lakes.

The correlation between fast flow and lake activity is notable on Kamb Ice Stream (Fig. 4, inset C). The downstream trunk of the ice stream was actively streaming until its sudden stagnation in the mid-19th century (Retzlaff and Bentley, 1993; Smith and others, 2002), while the tributary region continues to move at speeds comparable to those of adjacent ice-stream tributaries (Price and others, 2001). We only identified one active lake on the stagnant Kamb trunk $\left(\mathrm{KT}_{1}\right)$, compared to the twelve lakes $\left(\mathrm{K}_{1}-\mathrm{K}_{12}\right)$ found in the tributary region and in a tributary-like region of adjacent Raymond Ridge $\left(R_{1}\right)$. Observations of bed and surface topography show that meltwater generated in the Kamb Ice Stream tributary region flows mostly into Whillans Ice Stream (Anandakrishnan and Alley, 1997), and that thin ice and low flow velocities have produced freezing conditions in the Kamb trunk (Bougamont and others, 2003b). This suggests that the basal meltwater generated beneath the 
tributaries (Joughin and others, 2004a) is available locally to refill drained lakes on the tributary, but not in the trunk.

We have also identified active lakes in East Antarctica, where they are common in the lower catchments of the outlet glaciers draining through the Transantarctic Mountains. There are fifteen active lakes upstream of Byrd Glacier (Fig. 4), one upstream of Mulock Glacier (Fig. 1), one upstream of Lennox-King Glacier (Fig. 1) and a cluster of six on David Glacier (Fig. 4, inset F). We found three additional active lakes in the upper catchments of Ninnis and Totten Glaciers (Fig. 1, lower right quadrant), and one located in the main trunk of Lambert Glacier about $100 \mathrm{~km}$ upstream of the Amery Ice Shelf grounding line. Except for glaciers draining west into the Filchner Ice Shelf, there is no evidence of lake activity in Dronning Maud Land or Enderby Land, which together include about one-third of the Antarctic coastline. The bed in this region is generally above sea level, suggesting that the ice sole is not covered by marine sediments, and modeling (Llubes and others, 2006) suggests that basal temperatures are commonly below freezing point. In this area, the surface slope is relatively high compared to Victoria Land, George $\mathrm{V}$ Land and West Antarctica, and tributary flow is confined to within a few hundred kilometers of the coast. The higher surface slope makes trapping water more difficult, and the smaller extent of streaming flow reduces the area over which water can collect to resupply lakes.

\subsection{Completeness of the inventory, accuracy of volume changes}

We have no doubt that the inventory of active lakes is incomplete, likely missing many lakes in the northern regions of Antarctica where the ICESat track spacing is greatest. It is only in the southern part of ICESat's coverage area that the absence of detected lakes is strong evidence for the absence of active lakes. The ICESat reference tracks and lake outlines shown in Figure 4 give examples of the relative sizes of lakes and the gaps between ground tracks; the most unfavorable example shown (David Glacier (Fig. 4, inset F)) has about half the track-to-track spacing that is seen in northern parts of Antarctica. The scatter plot in Figure 5 shows the distribution of measured lake sizes, compared with the track-to-track spacing. To allow comparison with the track spacing, we parameterize the lake size as the diameter of a circle with the same area as the lake. The median lake size is $13 \mathrm{~km}$, which equals the track spacing at $\sim 80^{\circ} \mathrm{S}$. This means that tracks are increasingly unlikely to encounter lakes at latitudes north of this, and that the smaller lakes found farther to the north are likely to be poorly sampled. The histograms in Figure 5 show the latitudes at which we detected lakes, compared with the latitudinal distribution of Antarctica's grounded ice. If lakes were uniformly distributed across Antarctica, we would expect to see a distribution of lakes with latitude roughly matching the area distribution of grounded ice; instead we see that although $70 \%$ of our lakes are located south of $80^{\circ} \mathrm{S}$, this region encompasses less than a third of Antarctica's grounded area (Lythe and others, 2001). This may reflect the true distribution of lakes on the continent, but it is also easily explained by a geographic bias in our lake locations towards regions densely sampled by ICESat.

A second source of geographic bias in the lake locations comes from spatial variations in cloud cover and ice surface topography. In the East Antarctic interior, where

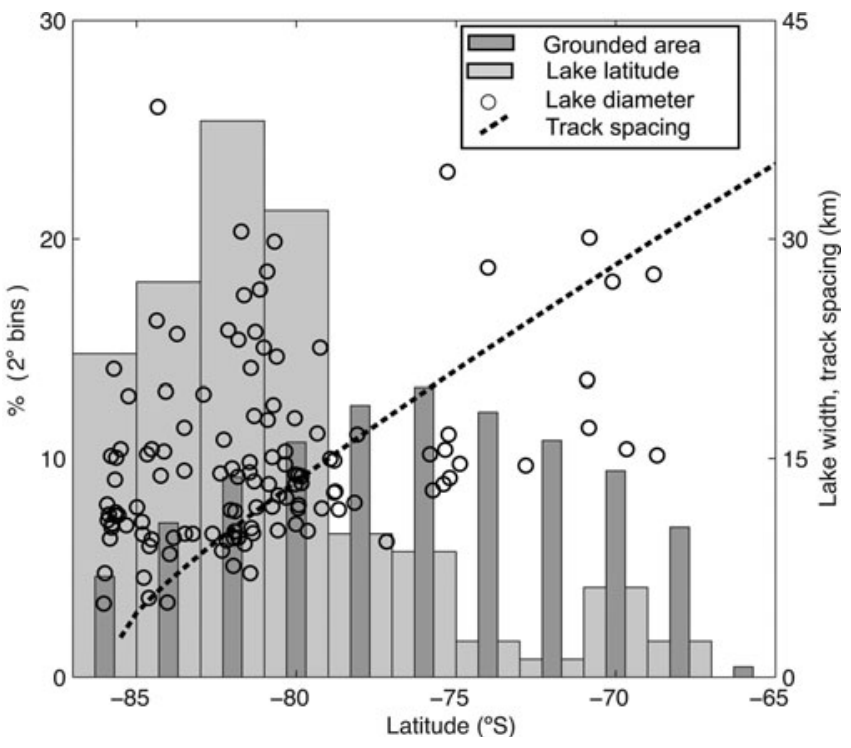

Fig. 5. Histograms of latitude of the 108 confidently identified active lakes under the Antarctic ice sheet identified in this study (light gray bars, scale at left) and continental grounded-ice area (dark gray bars, scale at left), with approximate lake widths (circles, scale at right) and inter-track spacing (dotted curve) plotted as a function of latitude.

surface slopes are small, surface velocity is low and heavy cloud cover is relatively rare, we attribute most apparent surface elevation change anomalies to active lakes. In regions with steeper surface topography, higher ice velocities and more cloud cover, however, spurious apparent elevation changes are more common (causes 1, 4 and 6, respectively, of section 3.2). For this reason, the fact that we have detected no lakes on, for example, the Amundsen Coast of West Antarctica, does not imply that there are none, although it suggests strongly that large active lakes are not common in this area.

The accuracy of our estimated volume ranges depends on the location and size of the lake in relation to the ICESat tracks that detected the elevation anomalies. One example of this is a large lake that we identified in the lower part of David Glacier, East Antarctica (Fig. 4, inset F). Based on an outline that encompasses a cluster of in-phase elevation changes, $D_{1}$ gained about $1.1 \mathrm{~km}^{3}$ between November 2003 and March 2008. Because only three ICESat tracks cross this lake, however, it is possible that the measured elevation changes reflect two or even three smaller lakes that all showed similar temporal patterns of elevation change. Were this true, the combined inferred volume gain of the two or three lakes would be considerably smaller, because their inferred surface area would be considerably smaller than that of the boundary that we interpreted for a single lake.

\subsection{Temporal patterns of water motion}

Estimated volume displacement rates for each lake varied widely (Fig. 6). Median per-lake peak volume displacement rates are on the order of $1 \mathrm{~m}^{3} \mathrm{~s}^{-1}$, although the highest rates were on the order of 100 times this. The smaller rates $\left(<10 \mathrm{~m}^{3} \mathrm{~s}^{-1}\right)$ are within the range that may be accommodated by channels incised in subglacial till (Walder and Fowler, 1994), which, in regions of low surface slope where till is present at the bed, are expected to be the dominant 


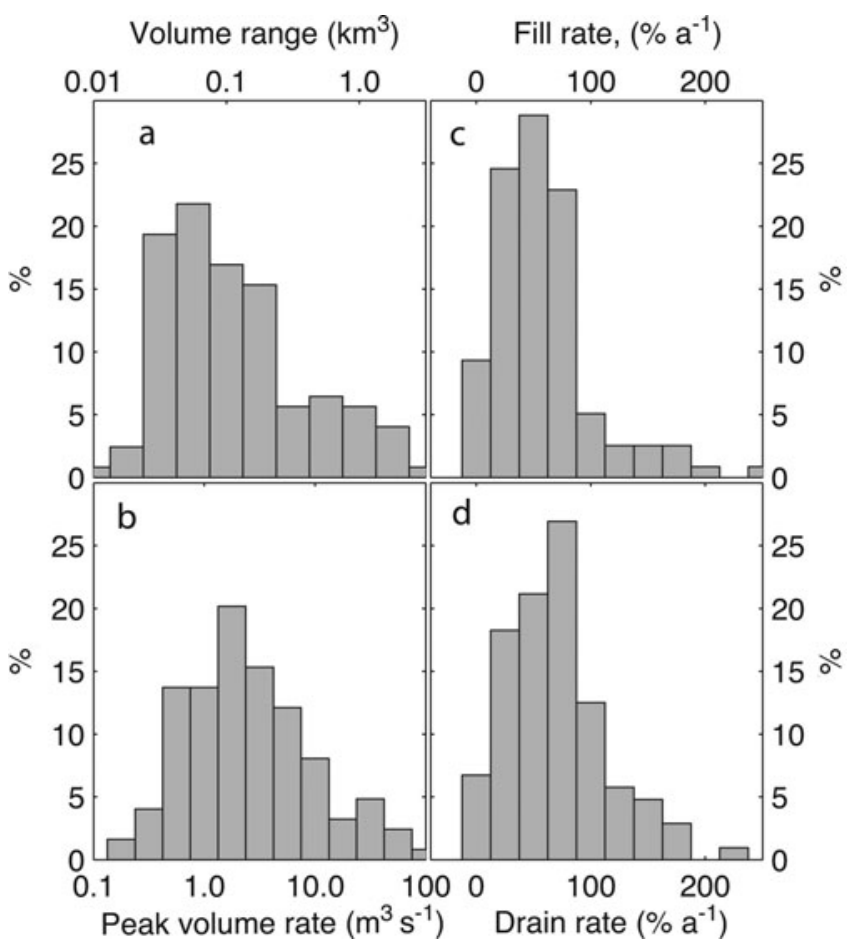

Fig. 6. Histograms of lake-volume ranges and rates for 124 active lakes under the Antarctic ice sheet identified in this study. (a) Total volume range, binned by $\log (\mathrm{d} V)$ in four bins per decade. (b) The peak rate of filling or drainage, binned by $\log (\mathrm{d} V / \mathrm{d} t)$ in four bins per decade. (c, d) Normalized filling (c) and drainage rates (d) for lakes, equal to the maximum measured rate of filling (or drainage) divided by the lake volume range, binned with a resolution of $25 \% \mathrm{a}^{-1}$.

mechanism of drainage. In such regions, discharge rates on the order of $100 \mathrm{~m}^{3} \mathrm{~s}^{-1}$ require effective pressures very close to zero (Walder and Fowler, 1994), which suggests that the largest water motions may strongly, if temporarily, increase basal lubrication.

Many lakes appear to show continuous drainage or filling for 3 or 4 years, much longer than is observed in subpolar outburst floods such as jökulhlaups (Ng and others, 2007). Although the time resolution of our measurements is coarse, and the filling and drainage of the lakes could take place by short episodes of rapid flow, we interpret these data as reflecting steady, rather than episodic, changes. Measurements with higher temporal resolution than ICESat's are required to disprove this interpretation. Analysis of the Adventure Trench flood (Carter and others, 2009) showed that subglacial conduits should take months to years to open to full capacity, given the low gradients in hydraulic potential in an ice sheet compared with the relatively steep hydraulic gradients found in subpolar subglacial water systems. A similar conclusion was reached in the analysis of a possible subglacial flood from Vostok Subglacial Lake (Evatt and others, 2006). Likewise, some of the more rapid events, including the Byrd drainage, appear to occur in areas where the surface slope and the resulting hydraulic gradient are relatively steep.

Over the measurement period, 2003-08, net lake fillings were approximately as common as net lake drainages, with $51 \%$ of lakes showing a net water gain. So that we can compare lake draining and filling events between lakes, even though total lake displacements vary by more than two orders of magnitude, we compute a normalized drainage and filling rate for each:

$$
\frac{\delta_{\mathrm{N}} V}{\delta t}=\frac{1}{\max (V)-\min (V)} \frac{V(t+\delta t)-V(t)}{\delta t} .
$$

This rate $\left(\mathrm{a}^{-1}\right)$ gives the displacement rate between subsequent observations of the lake volume, normalized by the total volume range for that lake. Figure $6 \mathrm{c}$ and $\mathrm{d}$ show maximum normalized filling and draining rates, respectively, for all lakes. On average, drainage rates were faster than filling rates: the median peak normalized drainage rate was $67 \% \mathrm{a}^{-1}$, while the median peak normalized filling rate was $48 \% \mathrm{a}^{-1}$. This observation is consistent with a model for subglacial lake filling and drainage proposed by Pattyn (2008), in which lakes passively accumulate water from an upstream source, gradually lifting the ice above the lake until the hydrologic potential of the lake surface exceeds the hydrologic potential at the lake outlet such that a selfenlarging conduit can begin to drain the lake.

\subsection{Spatio-temporal patterns of water motion: evidence for lake linkage}

Water motion in subglacial water systems may reflect water exchanges among lakes or water motion between lakes and an independent water system, such as distributed channels or cavities. No evidence constrains the possible length of channels linking lakes, and it is possible that lakes separated by hundreds of kilometers may show linked behavior. Indeed, previous studies of subglacial lakes (Gray and others, 2005; Wingham and others, 2006; Fricker and Scambos, 2009) have concluded that subglacial lakes are hydrologically linked, especially when the surface displacements for adjacent lakes suggested draining upstream and filling downstream. Collectively, however, these three studies observed only 14 active lakes, which allows the possibility that the apparent linkages they observed were coincidental. With our set of 124 active lakes throughout Antarctica, we are able to examine linkages more definitively. We found that different glacier systems exhibit varying degrees of linkages. As examples, three glacier catchments in the Filchner-Ronne region showed evidence of different lake linkage regimes: (1) Academy Glacier shows no apparent linkage between lakes; (2) Slessor Glacier shows apparent linkage between closely adjacent lakes; and (3) Recovery Glacier appears to show close linkage between lakes separated by hundreds of kilometers. We describe these three cases in more detail below, as well as some other systems around Antarctica that show less easily categorized patterns of lake-to-lake linkage. It is important to keep in mind that the results in this section are derived from gridded elevation displacements interpolated between sometimes widely spaced elevation anomaly measurements (section 3.3). These volume estimates have large (perhaps 50\%) uncertainties, and there is a second, potentially larger, uncertainty in estimating water-volume changes at the bed from surface volume changes (section 3.4). The patterns of water motion discussed here are likely to be more meaningful than the total water balance of any glacier's lakes.

\subsubsection{Academy Glacier: no apparent linkage}

The 16 active lakes we found beneath Academy Glacier (inset B of Figs 1 and 4) showed little correlation between activity cycles for adjacent lakes (Fig. 7). Two large lakes, $A_{5}$ and $A_{12}$, filled steadily throughout the study period, with volume ranges of 0.35 and $0.51 \mathrm{~km}^{3}$ respectively, and 


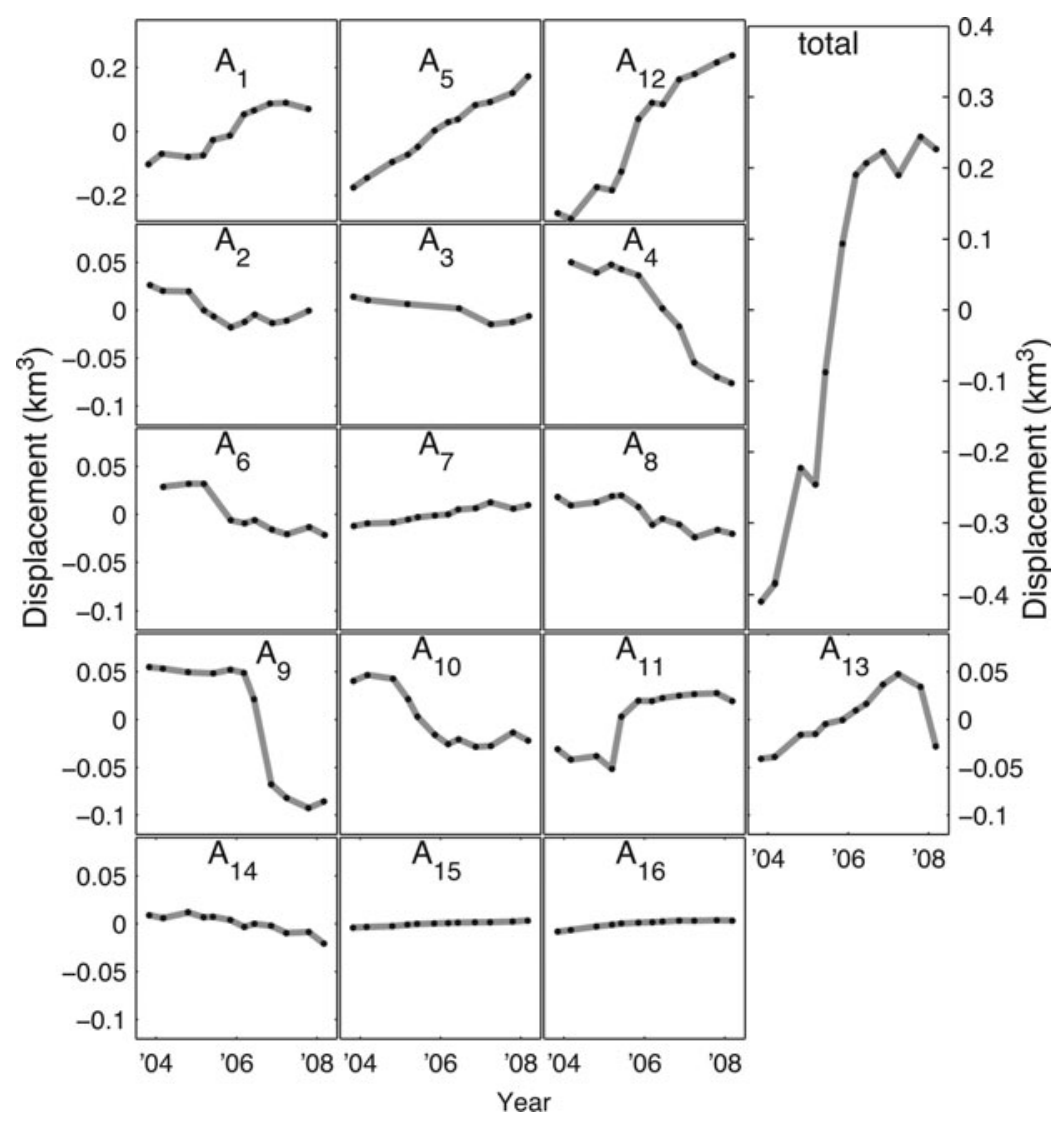

Fig. 7. Time series of volume displacements for 16 lakes on Academy Glacier $\left(A_{1}-A_{16} ;\right.$ Figs 1 and 4 for lake locations). Panels are ordered so that each row has a consistent volume scale, and all time series are plotted relative to the mean displacement for each lake. At top right is a plot of the time series of the total cumulative displacement for these 16 lakes. Timescale is $2000+$ year (AD).

dominate the water budget. Others displayed a wide range of behavior, with some lakes filling or draining steadily, while others showed sudden changes of only 1-2 years duration (e.g. $A_{9}-A_{11}, A_{13}$ ). There is no clear correlation between the inferred volume changes for these lakes, and adjacent lakes are about equally likely to have correlated or uncorrelated activity. Because the three largest lakes in the system all gained water, Academy Glacier as a whole had a net gain of $0.6 \mathrm{~km}^{3}$ between February 2004 and May 2006, when the drainage of lakes $\mathrm{A}_{4}$ and $\mathrm{A}_{9}$ began to counterbalance the gains in the larger lakes.

\subsubsection{Slessor Glacier: partial linkage}

Figure 8 shows the pattern of volume change for the six lakes found beneath Slessor Glacier (Fig. 4, inset A). Similar to Academy Glacier, three large lakes, $S_{1}, S_{2}$ and $S_{4}$, dominate the water balance. Because the larger two of these lakes filled during most of the measurement period, the total water balance for the ice stream was a net increase in storage by $0.94 \mathrm{~km}^{3}$. The Slessor Glacier lakes have the unusual property that two pairs appear to be linked, $\mathrm{S}_{2}$ with $S_{3}$ and $S_{4}$ with $S_{5}$. Lakes in these pairs were immediately adjacent to one another, and the upstream lakes showed small drainages early in the ICESat period, while the downstream lakes filled steadily over the ICESat period. This pattern may reflect a transfer of water from the upstream lake to the downstream lake, perhaps simultaneously with a transfer of water from a distributed water system into $S_{2}$ and $\mathrm{S}_{4}$. An alternative interpretation of this pattern is that increasing lubrication at the downstream lake caused a local acceleration of ice flow, leading to thinning upstream, as the spatial pattern of elevation change is similar to that expected for an ice-stream response to a change in basal lubrication (Sergienko and others, 2007). Because the upstream and downstream motions are of substantially different magnitude, it seems unlikely that lubrication changes alone could have produced this pattern of elevation change, and more likely that water motion played a role in the surface-elevation changes.

\subsubsection{Recovery Glacier: direct linkage}

Figure 9 shows similar plots for Recovery Glacier (Fig. 4, inset A). As with Academy and Slessor Glaciers, the water balance was dominated by three large lakes $\left(R_{1}, R_{3}\right.$ and $\left.R_{7}\right)$. Unlike those on the other two glaciers, however, the Recovery lakes show a spatial gradient in the lake water balances such that the lakes upstream of $\sim 500 \mathrm{~km}$ from the grounding line $\left(R_{7}-R_{10}\right)$ each had net drainage, while the lakes downstream of $\sim 500 \mathrm{~km}\left(R_{1}-R_{6}\right)$ had net filling, with the exception of $R_{4}$, at $275 \mathrm{~km}$, which drained. Together, the upstream lakes drained $\sim 3.0 \mathrm{~km}^{3}$ of water, while the downstream lakes filled by $\sim 3.1 \mathrm{~km}^{3}$. Because the drainage of the upstream lakes matched the filling of the downstream lakes, on a campaign-by-campaign basis, the total water budget of the ice stream varied by only $0.85 \mathrm{~km}^{3}$. Recovery Glacier is unusual in that large lakes have been located upstream of the active lakes (Bell and others, 2007) that might resupply some of the water that flowed from the lakes. Because these lakes have surface areas on the order of $6 \times 10^{3} \mathrm{~km}^{2}$, they could refill the $3 \mathrm{~km}^{3}$ gained by upper 


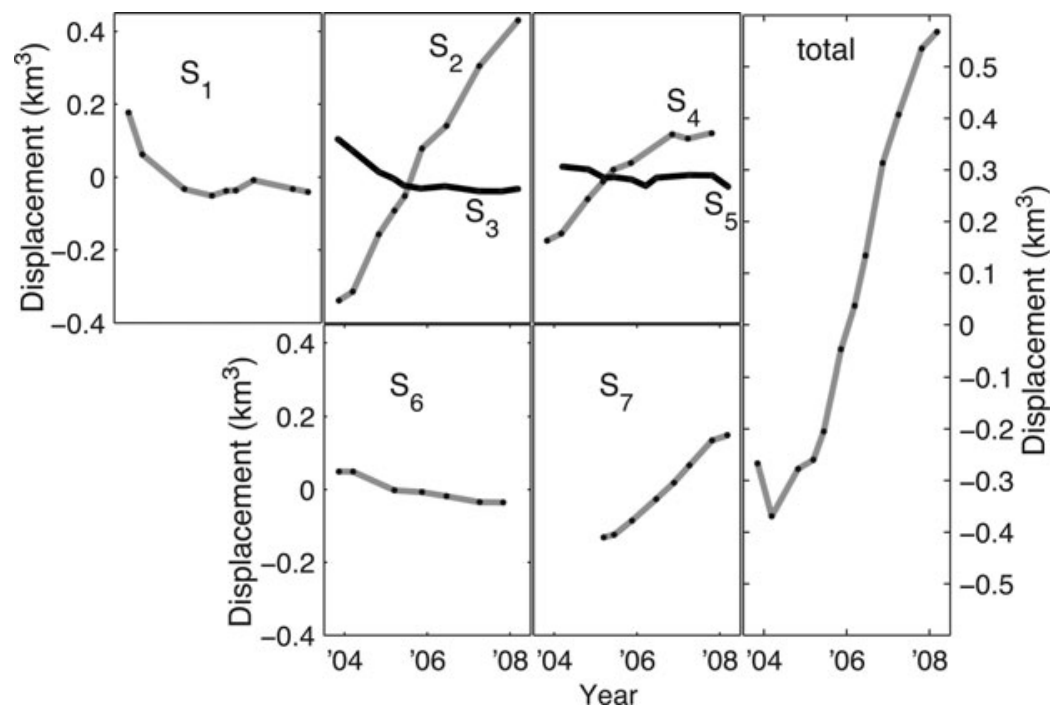

Fig. 8. Time series of volume displacements for seven lakes beneath Slessor Glacier ( $S_{1}-S_{7}$; Figs 1 and 4 for lake locations). Right plot is a time series of the total cumulative displacements for these seven lakes. Because $S_{2}$ and $S_{3}$ are adjacent, and $S_{4}$ and $S_{5}$ are adjacent, they are shown on the same axes, with the upstream member of the pair plotted in black.

Recovery Glacier lakes without a detectable change in their own surface elevation.

\subsubsection{Other hydrologic systems: varying degrees of linkage}

Other glacier catchments show behavior intermediate between the extremes represented by Academy Glacier and Recovery Glacier. In the Byrd Glacier catchment (Fig. 4, inset $\mathrm{E}$ ), which contains two large lakes $\left(\mathrm{By}_{1}\right.$ and $\mathrm{By}_{2}$ ) and fourteen small lakes $\left(B_{s 1}-B_{s 14}\right)$, the large lakes appear to be linked to an external water source: $B y_{2}$ filled steadily from November 2003 until November 2005, gaining $1.7 \mathrm{~km}^{3}$ (Fig. 10). It then drained until November 2006, losing $1.6 \mathrm{~km}^{3}$, and refilled by $0.9 \mathrm{~km}^{3}$ between May and October 2007. By $y_{1}$, which is slightly downstream of $\mathrm{By}_{2}$, showed a very similar pattern of displacements, delayed by about
6 months, suggesting that a traveling pulse of water reached $\mathrm{By}_{2}$ first, then moved downstream into $\mathrm{By}_{1}$. The smaller lakes in the catchment showed no strong evidence of influence from this process, showing instead a spatial division: lakes downstream of lake $B_{s 8}$ drained continually, while lake $B_{s 8}$ and all lakes upstream of it gained water steadily. Evidence presented elsewhere (Stearns and others, 2008) suggests that the water draining from these lakes flowed under the trunk of Byrd Glacier, producing a drop in basal resistance and an acceleration by about $10 \%$.

The lakes in the lower catchment of David Glacier (Fig. 1; Fig. 4, inset F) showed a pattern of activity similar (Fig. 11) to that of the Byrd lakes, with lake $\mathrm{D}_{3}$ draining until mid-2006, then refilling slightly, lake $\mathrm{D}_{2}$ draining until mid- to late 2006, and lake D1 filling throughout the mission. The volumes of these lakes are not well defined by the tracks,

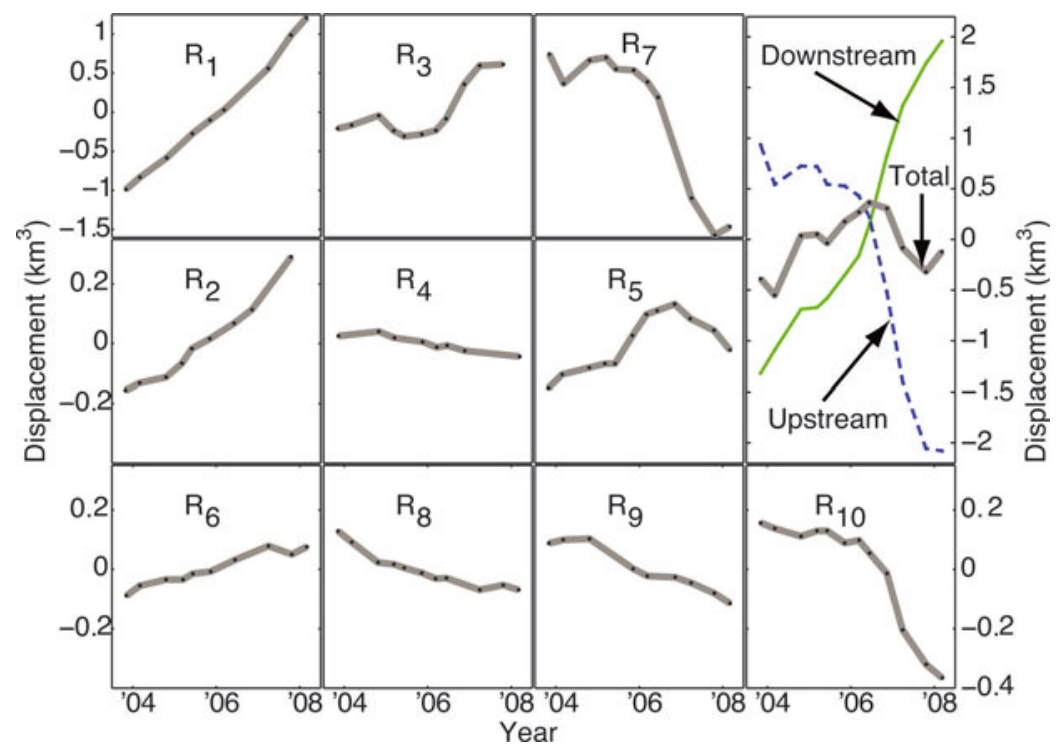

Fig. 9. Time series of volume displacements for ten lakes beneath Recovery Glacier $\left(R_{1}-R_{10}\right.$; Figs 1 and 4 for lake locations). Total displacements are divided into subtotals for lakes $R_{7}-R_{10}$ (blue dashed curve) and lakes $R 1-R_{6}$ (green curve); whole glacier total shown in gray. 


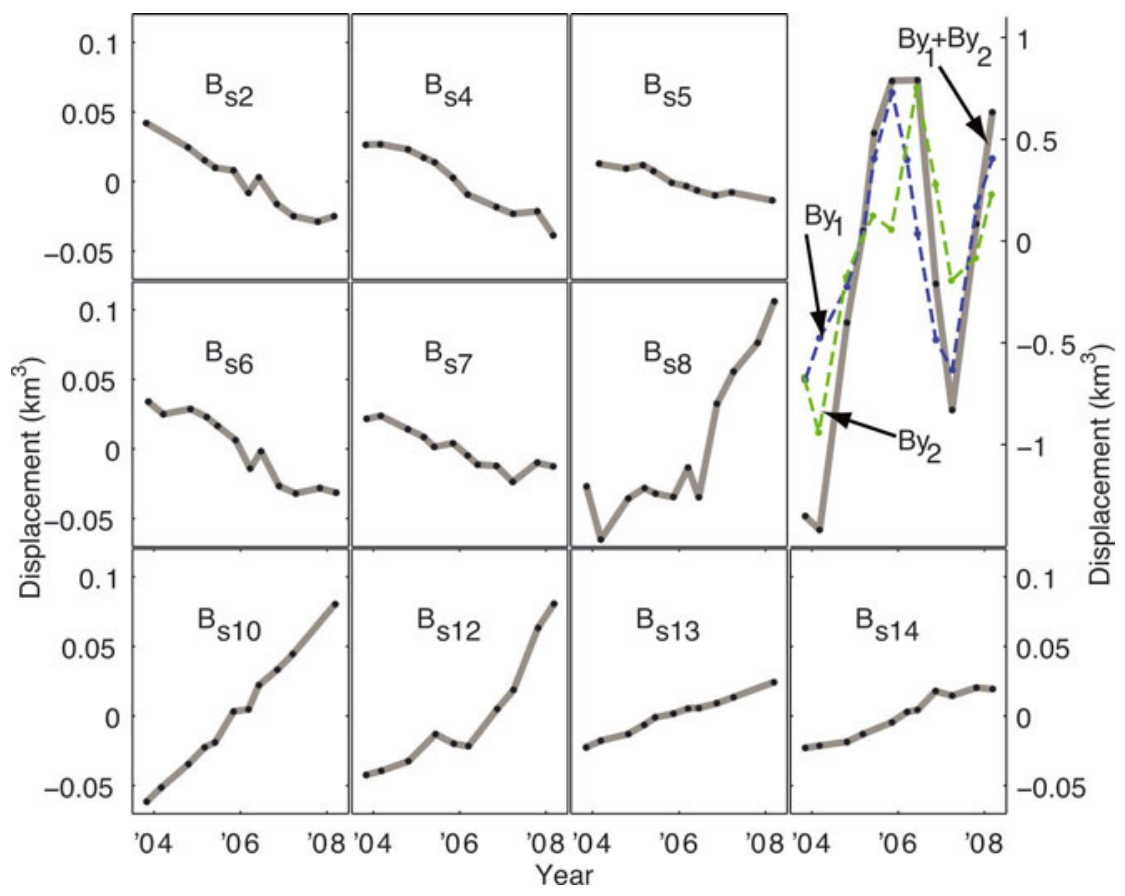

Fig. 10. Time series of volume displacements for selected lakes in the catchment of Byrd Glacier (Figs 1 and 4 for lake locations). Panel at right shows the displacements for lakes $\mathrm{B}_{1}$ (blue) and $\mathrm{B}_{2}$ (green) and their sum (gray).

and we cannot make robust inferences about the water balance of the system, but it is possible that the observed elevation changes show $D_{3}$ and $D_{2}$ draining into $D_{1}$, with $\mathrm{D}_{3}$ running out of water shortly before $\mathrm{D}_{2}$. No velocity measurements are available to show whether this water changed the speed of David Glacier.

Two lakes in George V Land, East Antarctica, in the eastern catchment of the Cook Ice Shelf (Fig. 1, bottom center), showed an apparent linkage similar to the two large lakes in the Byrd catchment. Just below the flow divide separating the Ross Sea drainage from the Pacific drainage, one lake, Cook $\mathrm{E} 2$, discharged $2.7 \mathrm{~km}^{3}$ of water between November 2006 and March 2008 (Fig. 12). This estimate is based on only two tracks, track 277 and track 1325, so the spatial pattern of volume loss is poorly constrained. The temporal pattern and elevation-change magnitude however, seem consistent for both tracks: track 227 shows constant elevation until November 2006, then a drop in elevation as large as $44 \mathrm{~m}$ between November 2006 and March 2008; track 1325 shows constant elevation until November 2006, then a sudden drop in elevation as large as $48 \mathrm{~m}$ between November 2006 and March 2008. These elevation changes are about five times larger than any others seen on other lakes. Directly downstream of Cook $\mathrm{E}_{2}$, at lake Cook $\mathrm{E}_{\mathrm{E} 1}$, the surface rose between March 2006 and October 2007; no good measurement was recovered for the spring of 2008. This lake was sampled by just one track, and the calculated $0.22 \mathrm{~km}^{3}$ volume gain was much smaller than the volume lost by Cook E2 , but the timing of the activity on the two lakes suggests that water moved rapidly downstream from Cook E2 $_{2}$ to Cook $_{\mathrm{E} 1}$ starting in late 2006.

A small cluster of five lakes near the southern limit of coverage on the East Antarctic plateau (Fig. 4, inset D), $E_{1}, E_{2}$, $E_{3}, E_{5}$ and $E_{6}$, showed a progressive drainage pattern (Fig. 12). $E_{6}$, the upstream-most lake, drained throughout the mission, $E_{5}$ and $E_{3}$ began draining simultaneously in late 2004, while $E_{1}$ and $E_{2}$ began draining 1 year later, in late 2005. Although this pattern suggests a downstream-propagating pulse of water pressure at the bed, $E_{4}$, which is directly between $E_{3}$ and $E_{5}$, filled steadily between 2004 and late 2008 and does not fit the same pattern. Because of their small areas and displacements, these lakes would not have been detected if they were even a few degrees farther north, so their detection is somewhat fortuitous; however, the remainder of the plateau close to $86^{\circ} \mathrm{S}$ shows no significant activity outside the Academy Glacier basin, despite comparably dense sampling.

Finally, the interconnections between the cluster of lakes in the tributary region of Kamb Ice Stream, West Antarctica (Fig. 13; Fig. 4, inset C), are ambiguous. Lakes $\mathrm{K}_{10}, \mathrm{~K}_{11}$ and $\mathrm{K}_{12}$ all filled steadily between late 2003 and late 2006, but $K_{12}$ drained between late 2006 and early 2008, while $K_{10}$

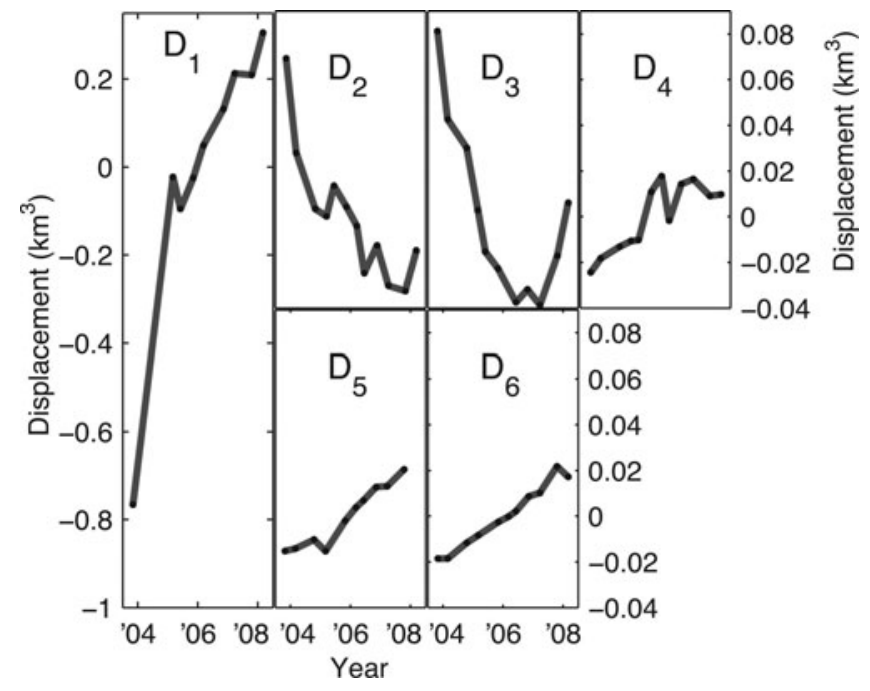

Fig. 11. Time series of volume displacements for six lakes on David Glacier (Figs 1 and 4 for lake locations). 


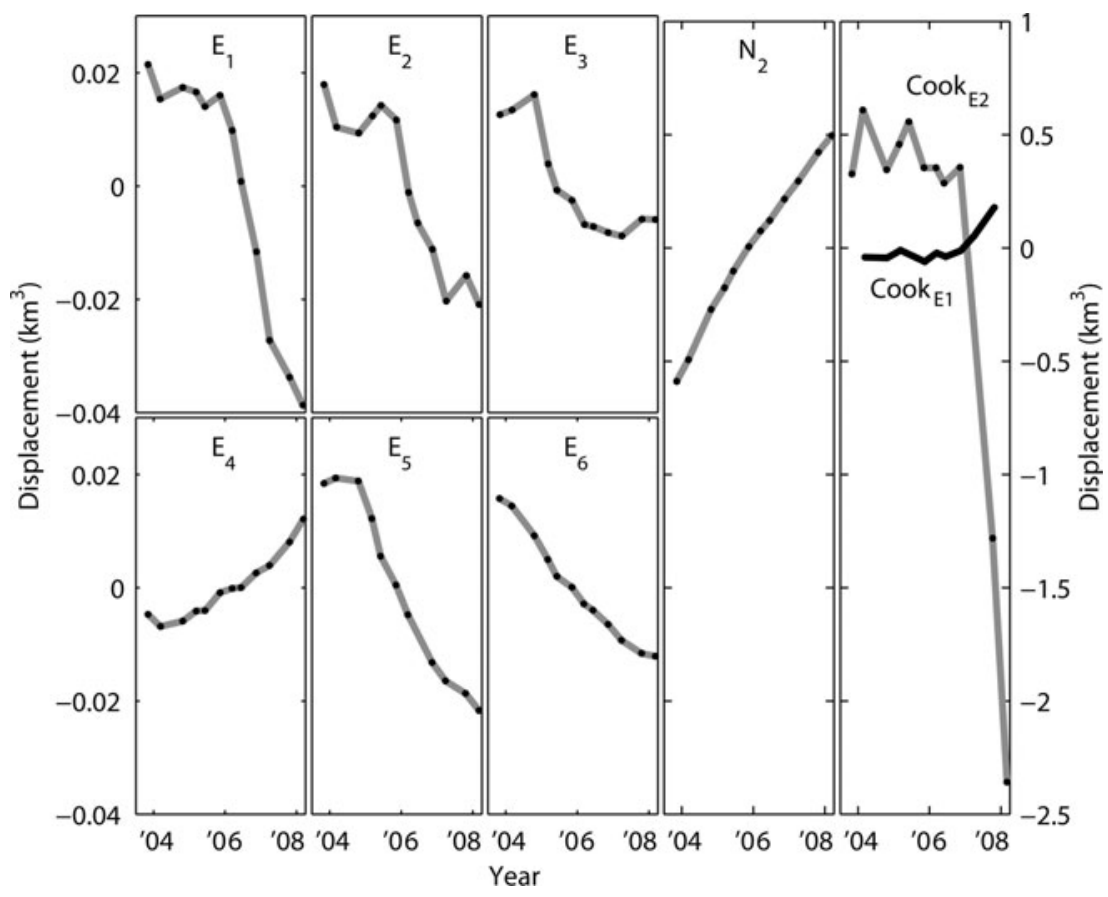

Fig. 12. Time series of volume displacements for selected lakes in the East Antarctic plateau (Figs 1 and 4 for lake locations). Cook ${ }_{E 1}$ and $\mathrm{Cook}_{\mathrm{E} 2}$, which appear to be linked, are shown on the same axes.

held steady and $\mathrm{K}_{11}$ filled. This may represent a hydrologic change at $\mathrm{K}_{12}$ that has not yet propagated downstream to $\mathrm{K}_{10}$ and $\mathrm{K}_{11}$, or the relationship between these three lakes may be coincidental. The lower lakes in the Kamb catchment $\left(\mathrm{K}_{1}-\mathrm{K}_{9}\right)$ do not show any easily interpretable pattern of changes.

\subsection{Duration of lake activity}

Prior to the ICESat mission, active lakes had been identified in the catchments of Kamb and Whillans Ice Streams on the Siple Coast (Gray and others, 2005), and beneath the East

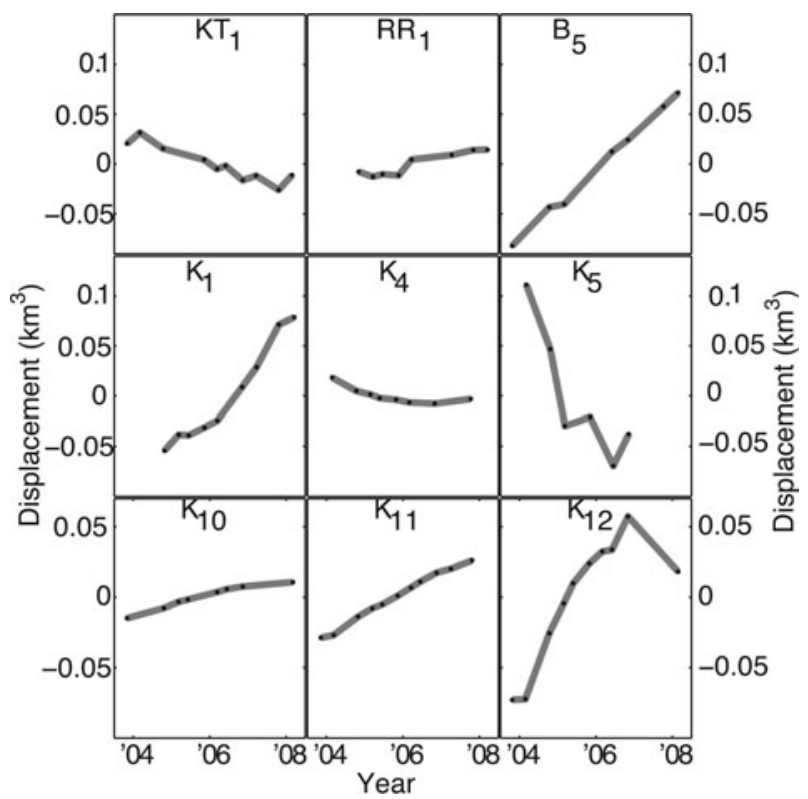

Fig. 13. Time series of volume displacements for selected lakes on Kamb Ice Stream, Bindschadler Ice Stream and Raymond interstream ridge (Figs 1 and 4 for lake locations).
Antarctic plateau (Wingham and others, 2006). We reexamined both of these systems using ICESat to find that evidence of previously measured activity was part of a longer-term process, rather than a one-time event in a transiently active system.

Two lakes in the Siple Coast region that were previously identified in interferometric radar records from 1997 are still active: lake Kamb ${ }_{10}$, which filled between November 2003 and November 2006, matches the location of a lake that was draining when observed in 1997; and lake Bindschadler ${ }_{5}$ which filled steadily throughout the ICESat mission, matches a pair of lakes, one that was draining in 1997, and one that was filling (Figs 4 and 13 for lake locations and volume histories).

In the Adventure Trench area of the East Antarctic plateau, one lake, $\mathrm{EAP}_{9}$, was close to the location of an active lake system measured by satellite radar altimetry, where surface motions suggested the drainage of an upstream lake into three downstream lakes between late 1996 and early 1998 (Wingham and others, 2006), with surface displacements between 0.5 and $1.0 \mathrm{~m}$. The ICESatdetected elevation change was smaller, with a surface rise of $0.4 \mathrm{~m}$ between late 2004 and early 2006, and an estimated volume gain of $0.45 \mathrm{~km}^{3}$. The center of $\mathrm{EAP}_{9}$ was $\sim 20 \mathrm{~km}$ from the center of the nearest of the 1996-98 locations, an area that inflated in 1996-98. Because the distance between this lake and the 1996-98 lakes is only a few times larger than the $2-3 \mathrm{~km}$ footprint of the radar altimeter, this location difference may not be significant. None of the other areas that changed in 1996-98 were observed to change during the ICESat period, suggesting that the remainder of the water system in this area was inactive between 2003 and 2008.

\subsection{Activity of RES-identified lakes}

Prior to this study, over 280 lakes had been located by RES surveys (Siegert and others, 2005; Carter and others, 2007; 
Popov and Masolov, 2007; Fig. 1). A particularly large concentration of lakes was found beneath the flanks of Dome C, East Antarctica, in the so-called 'Lakes District' (Siegert and others, 2005), and modeling based on balancevelocity estimates and geothermal heat-flux estimates from sparse geological information suggests the bed temperature is above the melting point over most of the area between $90^{\circ} \mathrm{E}$ and $180^{\circ} \mathrm{E}$ (Llubes and others, 2006). The only lakes for which rates of exchange of water with the surrounding ice sheet have been investigated in detail are the largest of these: Vostok Subglacial Lake and Lake Concordia in East Antarctica. RES (Bell and others, 2002) and isotopic (JeanBaptiste and others, 2001) measurements suggest small exchange rates for Vostok Subglacial Lake by basal freezing and melting, with water residence times in the lake on the order of $10^{4}-10^{5}$ years, and radar observations around Lake Concordia (Tikku and others, 2005) suggest similar residence times. For the purposes of this paper, these lakes are considered inactive, as they do not exchange large fractions of their volume on annual timescales.

The lakes found by RES surveys are generally small compared to the ICESat track spacing, and the published description of their location does not let us determine with certainty whether their locations have been sampled by ICESat. The RES surveys, which cover much of Antarctica, were conducted on $50 \mathrm{~km}$ grids (Siegert and others, 2005), suffer similar spatial sampling problems to the ICESat survey, and the ICESat survey should have encountered a random sample of lakes comparable in number to the RES surveys. Therefore, we take the absence of detected active lakes as evidence that most of the lakes in the Lakes District are not undergoing rapid changes, and that the water system around $E_{9}$ is exceptional in its level of activity. Evidence for complex subglacial hydrologic networks in the Lakes District extending several hundred kilometers has come from satellite radar altimetry analysis (Rémy and Legrésy, 2004), suggesting a pathway for water motion in this area; our study suggests that this network did not transport large, short-term water pulses during the 2003-08 observation interval.

The only active lake that was close to a lake identified by radar surveys was Vostok 1 (Figs 1 and 3), located about $10 \mathrm{~km}$ from the northeastern boundary of Vostok Subglacial Lake, and less than $5 \mathrm{~km}$ from a cluster of small lakes (Popov and Masolov, 2007). The gridded displacements over the ICESat period give a peak displacement rate of $-0.007 \mathrm{~km}^{3} \mathrm{a}^{-1}$ and a mean rate of $-0.004 \mathrm{~km}^{3} \mathrm{a}^{-1}$. As discussed earlier, the boundary for this lake is not well enough defined to give accurate volume estimates, but if this mean rate represents a long-term average drainage rate from Vostok Subglacial Lake, water flow through this lake amounts to about $2.5 \%$ of Vostok Subglacial Lake's estimated $0.15 \mathrm{~km}^{3} \mathrm{a}^{-1}$ water exchange with the ice sheet (Bell and others, 2002) through melt and freeze-on at the lake-ice interface. This type of connection between subglacial water systems and Vostok Subglacial Lake may help to explain the difference between the relatively long residence time inferred from internal layer geometry (13 ka (Bell and others, 2002)) and from models of ice-water exchanges that assume a closed system (32-55 ka (Studinger and others, 2004; Thoma and others, 2008)), and the shorter residence times (5 ka) inferred from helium isotope ratios in the frozen-on lake water (Jean-Baptiste and others, 2001). The lakes known from RES surveys within $50 \mathrm{~km}$ of the Vostok Subglacial Lake shore (Popov and
Masolov, 2007) did not appear to be active, but as they are small (2-4 km wide) it is likely that most were not sampled well by ICESat tracks and may also contribute to water exchanges with the lake.

Including the lakes discovered in this study, only five active lakes have been found in areas near ice divides: four near the Adventure Trench that were active between 1996 and 1998 (Wingham and others, 2006), and for which we observed continuing activity between 2003 and 2008 (i.e. $\left.\mathrm{E}_{9}\right)$, and lake Cook $_{\mathrm{E} 2}$. The lack of active lakes near ice divides likely reflects the limited availability of water to refill drained lakes in these areas. Their location near the ice-flow divide (assumed to match the hydrologic divide) limits the area from which they can collect water, and basal sliding is generally small or absent in divide regions, so the only heat available to generate meltwater is geothermal, producing repeat intervals for drainage sufficiently long that the 4.5 year ICESat survey only encountered two such lakes in an active phase. For comparison, in tributary and ice-stream regions, sliding at the bed supplies more than an order of magnitude more heat than geothermal heat flux (Joughin and others, 2004b, 2006).

\subsection{Effects of active lakes on ice dynamics}

Our observations of active lakes suggest they are potentially important to both the short-term and long-term glacier flow patterns. However, so far there has only been one direct connection found between changes in ice-flow rates and lake activity, on Byrd Glacier where lake drainage led to a temporary speed-up of the glacier trunk (Stearns and others, 2008). We believe the reason for the lack of information linking lake activity and ice dynamics is primarily because there are few repeat velocity measurements available during the ICESat period (2003-08), and not because such links do not exist.

Active lakes may affect ice dynamics and potentially icedischarge rates, both by perturbing the basal shear stress at the lake and by modifying the basal water system of the glacier. A lake exerts no basal shear stress on a glacier, so if a lake drains completely, the basal shear stress on the glacier will increase, leading to a decreased surface velocity. We have no evidence as to whether the lakes we observe ever drain completely, so we cannot determine whether they can influence ice dynamics in this way.

Even without draining completely, however, lakes can alter local discharge rates by adding water to or withdrawing water from the basal lubrication system in the glacier around them. In this case, a lake drainage would imply an increase in basal lubrication and a speed-up of the glacier, as was observed on Byrd Glacier (Stearns and others, 2008). Alternatively, lakes may act as sinks collecting water generated by melt over large areas, that then drains through isolated pathways to the ocean which, over longer periods, would reduce the mean lubrication over large areas of active ice streams. The sensitivity of a glacier to its subglacial lakes depends strongly on the nature of the ice-bed contact and on the spatial extent to which water is distributed across the ice-bed interface.

The slow drainage and filling rates observed in most lakes (section 4.4; Fig. 6) suggest that distributed channel systems in till may be important in most lake activity, but the larger events, including the Byrd lake drainage we know to have affected ice-discharge rates, are unlikely to have been accommodated only by channels in till. There may also be 
an asymmetry between the mechanisms for lake filling and lake drainage, with the lakes more often filling with water from distributed water systems, and more often draining into other lakes or into isolated pathways that connect to the ocean.

Where meltwater production has been estimated (Joughin and others, 2004b, 2006), annual production is of the same order of magnitude as the water fluxes into and out of the lakes observed in the 2003-08 time window (Fricker and others, 2007). This suggests these lakes have a strong influence on the basal water storage. The sign of the lakes' contribution varies from glacier to glacier, and we do not know whether this level of activity is typical of these lakes, but it seems possible that much of the water produced in these glaciers refills lakes, and that when these lakes drain, the water either flows to the ocean or into other downstream lakes. This would suggest that in these glaciers the active lakes are an important mechanism by which subglacial water is channeled to the ocean (Fricker and Scambos, 2009).

Whatever the uncertainties that remain as to the mechanisms of water transport beneath the ice sheet, our results show that theories of subglacial till and water systems that rely on a closed hydrologic system (e.g. Tulaczyk and others, 2000), where lubricating water must be supplied by local melt, and meltwater is locally available for lubrication, may overstate the short-term coupling between local melt and freeze rates and sliding. This is because where active lakes are present they may, at any time, add or remove water from the distributed basal hydrologic system. It is also possible that multiple subglacial water systems may coexist, some that are semi-permanent and are adapted to small flux rates and fed by slow rates of melt, and others that are established rapidly during drainage events. The 'slower' systems may leak into the lakes, contributing to lake filling.

\section{CONCLUSIONS}

We have presented a complete analysis of ICESat laser altimeter data between 2003 and 2008 that has identified 124 active subglacial lakes in Antarctica. The ICESat data show that active subglacial lakes are common throughout coastal Antarctica and are present in most of the largest drainage systems, which have the largest potential impacts on sea-level rise. Continuous monitoring of lakes should help in predictions of outlet glacier flow rates. The lakes observed in ice-penetrating radar surveys (Siegert and others, 2005) appear to be generally inactive, suggesting that the detection of subglacial lakes beneath a glacier does not necessarily imply a potential for basal-water-driven mass-balance changes. The active lake systems observed prior to ICESat (Gray and others, 2005; Wingham and others, 2006) are associated with continued elevation changes, suggesting that water systems may evolve over periods on the order of a decade or more.

The association between lake locations and ice-stream and tributary flow reflects the contrast in basal conditions between fast-flow areas and the surrounding ice sheet. In ice streams the two are linked by the availability of frictional heat to produce meltwater, and in the tributary region they may also be linked by the surface expression of basal topography and its influence on the hydrologic potential. Subglacial lakes are common in the catchments for the glaciers draining through the Transantarctic Mountains into the Ross Ice Shelf (Siegert and others, 2005), which implies that at least in some places, ice at the bed is melting, and basal melt from geothermal heating may funnel into the region near the outlets, allowing for an active water system.

Our data show that short-term changes in basal hydrologic systems are common throughout Antarctica. In most catchments, the lakes appear to exchange water with reservoirs undetectable by ICESat. This implies that in many parts of the ice sheet, water is available, both to the lakes, and from the lakes to the surrounding basal system, on annual and shorter timescales in volumes on the order of $0.1-1 \mathrm{~km}^{3}$. In a few cases, notably Recovery Glacier, large upstream reservoirs are known that might resupply some of the water (Bell and others, 2007) moving through the lake system, but in most other glaciers there is no known reservoir that could provide large quantities of water to refill drained lakes. In these, distributed sources of water such as linked cavities, distributed over a few thousand square kilometers, could supply a similar amount of water without producing surface-elevation changes detectable with ICESat data. This exchange may provide a mechanism for lakes to inject or withdraw water into systems that directly modify the basal shear stress of the glaciers. The widespread association of lakes with the ice streams most important to the ice sheet's mass balance, and their ability to quickly change the subglacial hydrological regime demonstrates that improvements in our understanding of subglacial hydrology are critical in understanding temporal changes in glacier flow and their contribution to sea-level change.

\section{ACKNOWLEDGEMENTS}

This work was supported by US National Science Foundation (NSF) grant ANT-0636719 to Joughin and Smith, NSF grant ANT-0636970 to Tulaczyk, and NASA grant NNX07AL18G to Fricker. We thank NASA's ICESat Science Project for distribution of the ICESat data (see http:// icesat.gsfc.nasa.gov and http://nsidc.org/data/icesat), and the members of the ICESat Science Team for discussions of data handling. We also thank R. Bell, G. Flowers and $\mathrm{N}$. Ross for thorough, critical and insightful reviews that greatly improved the paper. We thank S. Carter for helpful comments on the paper.

\section{REFERENCES}

Anandakrishnan, S. and R.B. Alley. 1997. Stagnation of Ice Stream C, West Antarctica by water piracy. Geophys. Res. Lett., 24(3), 265-268.

Bamber, J.L., J.L. Gomez-Dans and J.A. Griggs. 2008. A new 1 km digital elevation model of the Antarctic derived from combined satellite radar and laser data - Part 1: data and methods. Cryos. Discuss., 2(5), 811-841.

Bell, R.E., M. Studinger, A.A. Tikku, G.K.C. Clarke, M.M. Gutner and C. Meertens. 2002. Origin and fate of Lake Vostok water frozen to the base of the East Antarctic ice sheet. Nature, 416(6878), 307-310.

Bell, R.E., M. Studinger, C.A. Shuman, M.A. Fahnestock and I. Joughin. 2007. Large subglacial lakes in East Antarctica at the onset of fast-flowing ice streams. Nature, 445(7130), 904-907.

Bentley, C.R., N. Lord and C. Liu. 1998. Radar reflections reveal a wet bed beneath stagnant Ice Stream $C$ and a frozen bed beneath ridge BC, West Antarctica. J. Glaciol., 44(146), 149-156.

Bindschadler, R. and H. Choi. 2007. Increased water storage at ice-stream onsets: a critical mechanism? J. Glaciol., 53(181), 163-171. 
Bougamont, M., S. Tulaczyk and I. Joughin. 2003a. Numerical investigations of the slow-down of Whillans Ice Stream, West Antarctica: is it shutting down like Ice Stream C? Ann. Glaciol., 37, 239-246.

Bougamont, M., S. Tulaczyk and I. Joughin. 2003b. Response of subglacial sediments to basal freeze-on: 2. Application in numerical modeling of the recent stoppage of Ice Stream C, West Antarctica. J. Geophys. Res., 108(B4), 2223. (10.1019/ 2002JB001936.)

Budd, W.F., D. Jenssen and I.N. Smith. 1984. A three-dimensional time-dependent model of the West Antarctic ice sheet. Ann. Glaciol., 5, 29-36.

Carter, S.P., D.D. Blankenship, M.F. Peters, D.A. Young, J.W. Holt and D.L. Morse. 2007. Radar-based subglacial lake classification in Antarctica. Geochem., Geophys., Geosyst., 8(3), Q03016. (10.1029/2006GC001408.)

Carter, S.P., D.D. Blankenship, D.A. Young, M.E. Peters, J.W. Holt and M.J. Siegert. 2009. Dynamic distributed drainage implied by the flow evolution of the 1996-1998 Adventure Trench subglacial outburst flood. Earth Planet. Sci. Lett., 283(1-4), $24-37$.

Evatt, G.W., A.C. Fowler, C.D. Clark and N.R.J. Hulton. 2006. Subglacial floods beneath ice sheets. Philos. Trans. R. Soc London, Ser. A, 364(1844), 1769-1794.

Fricker, H.A. and L. Padman. 2006. Ice shelf grounding zone structure from ICESat laser altimetry. Geophys. Res. Lett., 33(15), L15502. (10.1029/2006GL026907.)

Fricker, H.A. and T. Scambos. 2009. Connected subglacial lake activity on lower Mercer and Whillans Ice Streams, West Antarctica, 2003-2008. J. Glaciol., 55(190), 303-315.

Fricker, H.A., T. Scambos, R. Bindschadler and L. Padman. 2007. An active subglacial water system in West Antarctica mapped from space. Science, 315(5818), 1544-1548.

Gray, L., I. Joughin, S. Tulaczyk, V.B. Spikes, R. Bindschadler and K. Jezek. 2005. Evidence for subglacial water transport in the West Antarctic ice sheet through three-dimensional satellite radar interferometry. Geophys. Res. Lett., 32(3), L03501. (10.1029/2004GL021387.)

Gudmundsson, G.H. 2003. Transmission of basal variability to a glacier surface. J. Geophys. Res., 108(B5), 2253. (10.1029/ 2002JB0022107.)

Harper, J.T., N.F. Humphrey, W.T. Pfeffer and B. Lazar. 2007. Two modes of accelerated glacier sliding related to water. Geophys. Res. Lett., 34(12), L12503 (10.1029/2007GL030233.)

Howat, I.M., S. Tulaczyk, E. Waddington and H. Björnsson. 2008. Dynamic controls on glacier basal motion inferred from surface ice motion. J. Geophys. Res., 113(F3), F03015. (10.1029/ 2007JF000925.)

Jean-Baptiste, P., J.R. Petit, V.Y. Lipenkov, D. Raynaud and N.I. Barkov. 2001. Constraints on hydrothermal processes and water exchange in Lake Vostok from helium isotopes. Nature, 411(6836), 460-462.

Joughin, I. and 7 others. 1999. Tributaries of West Antarctic ice streams revealed by RADARSAT interferometry. Science, 286(5438), 283-286.

Joughin, I., D.R. MacAyeal and S. Tulaczyk. 2004a. Basal shear stress of the Ross ice streams from control method inversion. J. Geophys. Res., 109(B9), B09405. (10.1029/ 2003JB002960.)

Joughin, I., S. Tulaczyk, D. MacAyeal and H. Engelhardt. 2004b. Melting and freezing beneath the Ross ice streams, Antarctica. J. Glaciol., 50(168), 96-108.

Joughin, I. and 10 others. 2005. Continued deceleration of Whillans Ice Stream, West Antarctica. Geophys. Res. Lett., 32(22), L22501. (10.1029/2005GL024319.)

Joughin, I., J.L. Bamber, T. Scambos, S. Tulaczyk, M. Fahnestock and D.R. MacAyeal. 2006. Integrating satellite observations with modelling: basal shear stress of the Filcher-Ronne ice streams, Antarctica. Philos. Trans. R. Soc. London, Ser. A, 364(1844), 1795-1814.
Joughin, I., S.B. Das, M.A. King, B.E. Smith, I.M. Howat and T. Moon. 2008. Seasonal speedup along the western flank of the Greenland Ice Sheet. Science, 320(5877), 781-783.

Kamb, B. 2001. Basal zone of the West Antarctic ice streams and its role in lubrication of their rapid motion. In Alley, R.B. and R.A. Bindschadler, eds. The West Antarctic ice sheet: behavior and environment. Washington, DC, American Geophysical Union, 157-199. (Antarctic Research Series 77.)

Kamb, B. and 7 others. 1985. Glacier surge mechanism: 19821983 surge of Variegated Glacier, Alaska. Science, 227(4686), 469-479.

Llubes, M., C. Lanseau and F. Rémy. 2006. Relations between basal condition, subglacial hydrological networks and geothermal flux in Antarctica. Earth Planet. Sci. Lett., 241(3-4), 655-662.

Lythe, M.B., D.G. Vaughan and BEDMAP consortium. 2001. BEDMAP: a new ice thickness and subglacial topographic model of Antarctica. J. Geophys. Res., 106(B6), 11,335-11,351.

$\mathrm{Ng}$, F., S. Liu, B. Mavlyudov and Y. Wang. 2007. Climatic control on the peak discharge of glacier outburst floods. Geophys. Res. Lett., 34(L21), L21503 (10.1029/2007GL031426.)

Pattyn, F. 2008. Investigating the stability of subglacial lakes with a full Stokes ice-sheet model. J. Glaciol., 54(185), 353-361.

Popov, S.V. and V.N. Masolov. 2007. Forty-seven new subglacial lakes in the $0-110^{\circ} \mathrm{E}$ sector of East Antarctica. J. Glaciol., 53(181), 289-297.

Price, S.F., R.A. Bindschadler, C.L. Hulbe and I.R. Joughin. 2001. Post-stagnation behavior in the upstream regions of Ice Stream C, West Antarctica. J. Glaciol., 47(157), 283-294.

Retzlaff, R. and C.R. Bentley. 1993. Timing of stagnation of Ice Stream C, West Antarctica, from short-pulse radar studies of buried surface crevasses. J. Glaciol., 39(133), 553-561.

Rémy, F. and B. Legrésy. 2004. Antarctic ice sheet shape response to changes in outlet flow boundary conditions. Global Planet. Change, 42(1-4), 133-142.

Robin, G.deQ., C.W.M. Swithinbank and B.M.E. Smith. 1970. Radio echo exploration of the Antarctic ice sheet. IASH Publ. 86 (Symposium at Hanover 1968 - Antarctic Glaciological Exploration (ISAGE)), 97-115.

Scambos, T.A., T.M. Haran, M.A. Fahnestock, T.H. Painter and J. Bohlander. 2007. MODIS-based Mosaic of Antarctica (MOA) datasets: continent-wide surface morphology and snow grain size. Remote Sens. Environ., 111(2-3), 242-257.

Sergienko, O.V., D.R. MacAyeal and R.A. Bindschadler. 2007. Causes of sudden, short-term changes in ice-stream surface elevation. Geophys. Res. Lett., 34(22), L22503. (10.1029/ 2007GL031775.)

Shepherd, A. and D. Wingham. 2007. Recent sea-level contributions of the Antarctic and Greenland ice sheets. Science, 315(5818), 1529-1532.

Siegert, M.J. and J.L. Bamber. 2000. Correspondence. Subglacial water at the heads of Antarctic ice-stream tributaries. J. Glaciol., 46(155), 702-703.

Siegert, M.J., S. Carter, I. Tabacco, S. Popov and D.D. Blankenship. 2005. A revised inventory of Antarctic subglacial lakes. Antarct. Sci., 17(3), 453-460.

Smith, B.E., N.E. Lord and C.R. Bentley. 2002. Crevasse ages on the northern margin of Ice Stream C, West Antarctica. Ann. Glaciol., 34, 209-216.

Smith, B.E., C.R. Bentley and C.F. Raymond. 2005. Recent elevation changes on the ice streams and ridges of the Ross Embayment from ICESat crossovers. Geophys. Res. Lett., 32(21), L21S09. (10.1029/2005GL024365.)

Stearns, L.A., B.E. Smith and G.S. Hamilton. 2008. Increased flow speed on a large East Antarctic outlet glacier caused by subglacial floods. Nature Geosci., 1(12), 827-831.

Studinger, M., R.E. Bell, D.D. Blankenship, C.A. Finn, R.A. Arko and D.L. Morse. 2001. Subglacial sediments: a regional geological template for ice flow in West Antarctica. Geophys. Res. Lett., 28(18), 3493-3496. 
Studinger, M. and 11 others. 2003. Ice cover, landscape setting, and geological framework of Lake Vostok, East Antarctica. Earth Planet. Sci. Lett., 205(3-4), 195-210.

Studinger, M., R.E. Bell and A.A. Tikku. 2004. Estimating the depth and shape of Lake Vostok's water cavity from aerogravity data. Geophys. Res. Lett., 31(12), L12401. (10.1029/2004GL019801.)

Thoma, M., C. Mayer and K. Grosfeld. 2008. Sensitivity of subglacial Lake Vostok's flow regime on environmental parameters. Earth Planet. Sci. Lett., 269(1-2), 242-247.

Tikku, A.A., R.E. Bell, M. Studinger, G.K.C. Clarke, I. Tabacco and F. Ferraccioli. 2005. Influx of meltwater to subglacial Lake Concordia, East Antarctica. J. Glaciol., 51(172), 96-104.
Truffer, M. and M. Fahnestock. 2007. Climate change: rethinking ice sheet time scales. Science, 315(5818), 1508-1510.

Tulaczyk, S.M., B. Kamb and H.F. Engelhardt. 2000. Basal mechanics of Ice Stream B, West Antarctica. II. Undrainedplastic-bed model. J. Geophys. Res., 105(B1), 483-494.

Walder, J.S. and A. Fowler. 1994. Channelized subglacial drainage over a deformable bed. J. Glaciol., 40(134), 3-15.

Wingham, D.J., M.J. Siegert, A. Shepherd and A.S. Muir. 2006. Rapid discharge connects Antarctic subglacial lakes. Nature, 440(7087), 1033-1036.

Zwally, H.J., W. Abdalati, T. Herring, K. Larson, J. Saba and K. Steffen. 2002. Surface melt-induced acceleration of Greenland ice-sheet flow. Science, 297(5579), 218-222.

\section{APPENDIX}

Table 4. Parameters for all lakes discussed in this paper. The columns give the lake name and number, the number of tracks crossing each lake, the constraint ratio as defined in section 3.3, the latitude and longitude of the center of the lake, and, for each time period during which the lake's volume changed, the start and the end of the period (month/year +2000$)$ and the magnitude of the volume change

\begin{tabular}{|c|c|c|c|c|c|c|c|}
\hline Name & $\#$ tracks & $R_{\text {constraint }}$ & $\begin{array}{l}\text { Lat. } \\
{ }^{\circ} \mathrm{N}\end{array}$ & $\begin{array}{c}\text { Long. } \\
{ }^{\circ} \mathrm{E}\end{array}$ & Start & End & $\begin{array}{c}\mathrm{d} V \\
\mathrm{~km}^{3}\end{array}$ \\
\hline Academy $_{1}$ & 5 & 0.9 & -84.135 & -61.337 & $\begin{array}{l}10 / 03 \\
3 / 07\end{array}$ & $\begin{array}{c}3 / 07 \\
10 / 07\end{array}$ & $\begin{array}{c}0.19 \\
-0.019\end{array}$ \\
\hline Academy $_{2}$ & 4 & 1.0 & -84.536 & -57.445 & $11 / 03$ & $6 / 05$ & -0.033 \\
\hline Academy $_{3}$ & 2 & 1.0 & -84.608 & -59.082 & $\begin{array}{c}11 / 03 \\
4 / 07\end{array}$ & $\begin{array}{l}4 / 07 \\
3 / 08\end{array}$ & $\begin{array}{c}-0.029 \\
0.0087\end{array}$ \\
\hline Academy $_{4}$ & 4 & 1.0 & -84.810 & -55.730 & $3 / 04$ & $3 / 08$ & -0.13 \\
\hline Academy $_{5}$ & 5 & 1.0 & -84.836 & -53.700 & $10 / 03$ & 3/08 & 0.35 \\
\hline Academy ${ }_{6}$ & 7 & 1.0 & -85.316 & -55.218 & $3 / 05$ & $3 / 08$ & -0.053 \\
\hline Academy $_{7}$ & 8 & 1.0 & -85.565 & -53.722 & $11 / 03$ & $11 / 06$ & 0.019 \\
\hline Academy $_{8}$ & 11 & 1.0 & -85.651 & -52.932 & $6 / 05$ & $4 / 07$ & -0.044 \\
\hline Academy $_{9}$ & 13 & 1.0 & -85.865 & -52.231 & $3 / 06$ & $3 / 08$ & -0.13 \\
\hline Academy $_{10}$ & 11 & 1.0 & -85.768 & -50.995 & $10 / 04$ & $3 / 06$ & -0.067 \\
\hline Academy $_{11}$ & 35 & 1.0 & -85.797 & -48.408 & $\begin{array}{l}11 / 03 \\
3 / 05\end{array}$ & $\begin{array}{l}3 / 05 \\
6 / 06\end{array}$ & $\begin{array}{c}-0.02 \\
0.073\end{array}$ \\
\hline Academy $_{12}$ & 17 & 1.0 & -85.712 & -45.375 & $11 / 03$ & $3 / 08$ & 0.5 \\
\hline Academy $_{13}$ & 15 & 1.0 & -85.644 & -42.414 & $\begin{array}{c}11 / 03 \\
4 / 07\end{array}$ & $\begin{array}{l}4 / 07 \\
3 / 08\end{array}$ & $\begin{array}{r}0.088 \\
-0.075\end{array}$ \\
\hline Academy $_{14}$ & 10 & 1.0 & -85.776 & -39.569 & $5 / 05$ & $3 / 08$ & -0.028 \\
\hline Academy $_{15}$ & 14 & 1.0 & -86.023 & -37.687 & $10 / 03$ & $3 / 08$ & 0.0074 \\
\hline Academy $_{16}$ & 29 & 1.0 & -85.992 & -35.699 & $11 / 03$ & $3 / 08$ & 0.012 \\
\hline Bindschadler $_{1}$ & 3 & 0.8 & -80.347 & -131.503 & $3 / 05$ & $11 / 07$ & 0.19 \\
\hline Bindschadler $_{2}$ & 1 & 0.7 & -79.945 & -130.196 & $3 / 05$ & $11 / 06$ & 0.027 \\
\hline Bindschadler $_{3}$ & 1 & 0.7 & -80.027 & -126.645 & $6 / 05$ & $4 / 07$ & -0.068 \\
\hline Bindschadler $_{4}$ & 2 & 0.7 & -80.727 & -125.572 & $10 / 03$ & $2 / 08$ & 0.12 \\
\hline Bindschadler $_{5}$ & 3 & 0.6 & -80.610 & -123.994 & $10 / 03$ & $2 / 08$ & 0.15 \\
\hline Bindschadler $_{6}$ & 1 & 0.8 & -80.567 & -122.628 & $10 / 03$ & $10 / 07$ & 0.045 \\
\hline Byrd $_{1}$ & 3 & 0.8 & -81.026 & 148.302 & $\begin{array}{c}11 / 03 \\
3 / 04 \\
6 / 06 \\
3 / 07\end{array}$ & $\begin{array}{l}3 / 04 \\
6 / 06 \\
3 / 07 \\
2 / 08\end{array}$ & $\begin{array}{c}-0.25 \\
1.7 \\
-0.92 \\
0.42\end{array}$ \\
\hline Byrd $_{2}$ & 3 & 0.6 & -80.684 & 146.887 & $\begin{array}{c}11 / 03 \\
11 / 05 \\
3 / 07\end{array}$ & $\begin{array}{c}11 / 05 \\
3 / 07 \\
3 / 08\end{array}$ & $\begin{array}{c}1.4 \\
-1.4 \\
1\end{array}$ \\
\hline Byrd $_{\mathrm{s} 1}$ & 2 & 0.6 & -80.337 & 152.188 & $3 / 04$ & 3/08 & 0.072 \\
\hline Byrd $_{\mathrm{s} 2}$ & 2 & 0.8 & -80.762 & 149.534 & $10 / 03$ & $2 / 08$ & -0.067 \\
\hline Byrd $_{\text {s3 }}$ & 2 & 0.8 & -81.804 & 149.610 & $3 / 05$ & $10 / 07$ & -0.064 \\
\hline Byrd $_{\mathrm{s} 4}$ & 2 & 0.9 & -80.750 & 143.711 & $11 / 03$ & $3 / 08$ & -0.065 \\
\hline Byrd $_{\mathrm{s} 5}$ & 2 & 1.0 & -80.577 & 143.378 & $3 / 05$ & $2 / 08$ & -0.025 \\
\hline Byrd $_{\mathrm{s} 6}$ & 2 & 0.9 & -80.324 & 143.659 & $11 / 04$ & $4 / 07$ & -0.06 \\
\hline Byrd $_{\text {s7 }}$ & 2 & 1.0 & -80.034 & 143.739 & $3 / 04$ & $6 / 06$ & -0.035 \\
\hline Byrd $_{\mathrm{s} 8}$ & 1 & 1.0 & -80.012 & 142.407 & $6 / 06$ & $3 / 08$ & 0.14 \\
\hline Byrd $_{s 9}$ & 1 & 0.8 & -81.467 & 142.305 & $3 / 05$ & $2 / 08$ & 0.044 \\
\hline
\end{tabular}


Table 4. Continued

\begin{tabular}{|c|c|c|c|c|c|c|c|}
\hline Name & \# tracks & $R_{\text {constraint }}$ & $\begin{array}{l}\text { Lat. } \\
{ }^{\circ} \mathrm{N}\end{array}$ & $\begin{array}{l}\text { Long. } \\
{ }^{\circ} \mathrm{E}\end{array}$ & Start & End & $\begin{array}{l}\mathrm{d} V \\
\mathrm{~km}^{3}\end{array}$ \\
\hline Byrd $_{s 10}$ & 3 & 1.0 & -81.830 & 139.028 & 10/03 & $3 / 08$ & 0.14 \\
\hline Byrd $_{s 11}$ & 2 & 1.0 & -81.466 & 138.588 & $2 / 04$ & $2 / 08$ & -0.027 \\
\hline Byrd $_{s 12}$ & 2 & 0.8 & -80.900 & 138.237 & $11 / 03$ & $3 / 08$ & 0.12 \\
\hline Byrd $_{s 13}$ & 1 & 0.9 & -78.932 & 142.828 & $11 / 03$ & $3 / 08$ & 0.047 \\
\hline Byrd $_{\mathrm{s} 14}$ & 2 & 0.9 & -78.818 & 139.872 & $11 / 03$ & $3 / 08$ & 0.042 \\
\hline Byrd $_{s 15}$ & 2 & 1.0 & -78.806 & 138.957 & $10 / 04$ & $2 / 08$ & -0.035 \\
\hline Cook $_{\text {E1 }}$ & 1 & 0.5 & -71.872 & 155.337 & 6/06 & $10 / 07$ & 0.22 \\
\hline Cook $_{\text {E2 }}$ & 2 & 0.9 & -72.803 & 155.786 & $11 / 06$ & $3 / 08$ & -2.7 \\
\hline Cook $_{W 1}$ & 1 & 0.6 & -69.657 & 149.712 & $10 / 04$ & $3 / 06$ & -0.11 \\
\hline Cookw2 $_{\text {W }}$ & 1 & 0.7 & -70.839 & 149.379 & $\begin{array}{c}10 / 03 \\
6 / 06\end{array}$ & $\begin{array}{l}6 / 06 \\
3 / 08\end{array}$ & $\begin{array}{c}-0.078 \\
0.07\end{array}$ \\
\hline David $_{1}$ & 3 & 0.4 & -75.270 & 157.213 & $11 / 03$ & $3 / 08$ & 1.1 \\
\hline David $_{2}$ & 1 & 0.5 & -75.332 & 155.520 & $11 / 03$ & $6 / 06$ & -0.092 \\
\hline David $_{3}$ & 2 & 0.9 & -75.240 & 152.918 & $\begin{array}{c}11 / 03 \\
6 / 06\end{array}$ & $\begin{array}{l}6 / 06 \\
2 / 08\end{array}$ & $\begin{array}{c}-0.12 \\
0.044\end{array}$ \\
\hline David $_{4}$ & 2 & 0.9 & -75.732 & 152.250 & $11 / 03$ & $11 / 05$ & 0.035 \\
\hline David $_{5}$ & 2 & 0.9 & -74.879 & 152.461 & $3 / 05$ & 10/07 & 0.036 \\
\hline David $_{6}$ & 2 & 1.0 & -75.391 & 145.239 & $10 / 03$ & $3 / 08$ & 0.036 \\
\hline $\mathrm{EAP}_{1}$ & 10 & 1.0 & -85.839 & 140.641 & $11 / 05$ & $3 / 08$ & -0.055 \\
\hline $\mathrm{EAP}_{2}$ & 13 & 1.0 & -85.679 & 135.484 & $11 / 05$ & $4 / 07$ & -0.032 \\
\hline $\mathrm{EAP}_{3}$ & 25 & 1.0 & -85.902 & 132.796 & $\begin{array}{c}11 / 03 \\
10 / 04 \\
3 / 07\end{array}$ & $\begin{array}{c}10 / 04 \\
3 / 07 \\
3 / 08\end{array}$ & $\begin{array}{c}0.0034 \\
-0.025 \\
0.0029\end{array}$ \\
\hline $\mathrm{EAP}_{4}$ & 16 & 1.0 & -85.912 & 128.371 & $6 / 05$ & $3 / 08$ & 0.016 \\
\hline $\mathrm{EAP}_{5}$ & 10 & 1.0 & -85.662 & 124.417 & $10 / 04$ & $3 / 08$ & -0.041 \\
\hline $\mathrm{EAP}_{6}$ & 10 & 1.0 & -85.489 & 104.036 & $10 / 03$ & $3 / 08$ & -0.028 \\
\hline $\mathrm{EAP}_{7}$ & 2 & 1.0 & -83.967 & 122.437 & $\begin{array}{l}10 / 03 \\
10 / 07\end{array}$ & $\begin{array}{c}10 / 07 \\
3 / 08\end{array}$ & $\begin{array}{l}-0.04 \\
0.0033\end{array}$ \\
\hline $\mathrm{EAP}_{8}$ & 1 & 1.0 & -75.193 & 109.854 & $11 / 03$ & $3 / 08$ & -0.031 \\
\hline $\mathrm{EAP}_{9}$ & 1 & 0.8 & -75.808 & 135.558 & $11 / 03$ & $3 / 08$ & 0.047 \\
\hline Foundation $_{1}$ & 5 & 0.8 & -84.522 & -73.662 & $11 / 05$ & $4 / 07$ & -0.22 \\
\hline Foundation $_{2}$ & 6 & 1.0 & -84.984 & -73.971 & $\begin{array}{l}3 / 05 \\
3 / 07\end{array}$ & $\begin{array}{l}3 / 07 \\
3 / 08\end{array}$ & $\begin{array}{r}0.084 \\
-0.048\end{array}$ \\
\hline Foundation $_{3}$ & 28 & 1.0 & -85.258 & -72.793 & $\begin{array}{c}3 / 05 \\
11 / 06\end{array}$ & $\begin{array}{c}11 / 06 \\
3 / 08\end{array}$ & $\begin{array}{c}0.16 \\
-0.036\end{array}$ \\
\hline Institute $_{\mathrm{E} 2}$ & 2 & 0.9 & -82.625 & -79.013 & $10 / 03$ & $2 / 08$ & 0.12 \\
\hline Institute $_{\mathrm{W} 1}$ & 2 & 0.8 & -81.401 & -77.545 & 11/03 & $3 / 08$ & 0.07 \\
\hline Institute $_{W 2}$ & 2 & 0.7 & -81.628 & -83.579 & $\begin{array}{c}3 / 04 \\
10 / 04\end{array}$ & $\begin{array}{c}10 / 04 \\
2 / 08\end{array}$ & $\begin{array}{c}0.0054 \\
-0.071\end{array}$ \\
\hline Kamb trunk ${ }_{1}$ & 2 & 0.6 & -81.951 & -140.402 & $11 / 03$ & $2 / 08$ & -0.031 \\
\hline $\mathrm{Kamb}_{1}$ & 3 & 0.7 & -82.011 & -131.204 & $10 / 04$ & $3 / 08$ & 0.13 \\
\hline $\mathrm{Kamb}_{2}$ & 2 & 0.9 & -82.185 & -129.839 & $3 / 04$ & $3 / 06$ & -0.019 \\
\hline $\mathrm{Kamb}_{3}$ & 2 & 0.8 & -81.938 & -128.597 & $2 / 04$ & $10 / 07$ & -0.053 \\
\hline $\mathrm{Kamb}_{4}$ & 2 & 0.9 & -81.970 & -127.442 & $\begin{array}{c}2 / 04 \\
11 / 06\end{array}$ & $\begin{array}{l}11 / 06 \\
10 / 07\end{array}$ & $\begin{array}{c}-0.026 \\
0.0044\end{array}$ \\
\hline $\mathrm{Kamb}_{5}$ & 3 & 0.9 & -82.274 & -127.482 & $3 / 04$ & $11 / 06$ & -0.15 \\
\hline $\mathrm{Kamb}_{6}$ & 2 & 0.9 & -82.058 & -124.341 & $10 / 03$ & $2 / 08$ & 0.035 \\
\hline $\mathrm{Kamb}_{7}$ & 2 & 1.0 & -81.921 & -123.440 & $10 / 04$ & $10 / 07$ & 0.025 \\
\hline $\mathrm{Kamb}_{8}$ & 4 & 1.0 & -82.376 & -123.143 & $2 / 04$ & $2 / 08$ & -0.017 \\
\hline $\mathrm{Kamb}_{9}$ & 2 & 1.0 & -82.321 & -121.629 & $6 / 05$ & $10 / 07$ & 0.039 \\
\hline $\mathrm{Kamb}_{10}$ & 1 & 1.0 & -81.446 & -120.134 & $11 / 03$ & $3 / 08$ & 0.026 \\
\hline $\mathrm{Kamb}_{11}$ & 2 & 1.0 & -81.251 & -120.141 & $11 / 03$ & $10 / 07$ & 0.055 \\
\hline $\mathrm{Kamb}_{12}$ & 2 & 0.9 & -80.854 & -117.075 & $\begin{array}{l}10 / 03 \\
10 / 06\end{array}$ & $\begin{array}{c}10 / 06 \\
2 / 08\end{array}$ & $\begin{array}{c}0.13 \\
-0.039\end{array}$ \\
\hline Lambert $_{1}$ & 2 & 0.5 & -74.000 & 68.276 & $10 / 03$ & $6 / 06$ & -0.81 \\
\hline Lennox-King $_{1}$ & 3 & 0.9 & -84.773 & 157.119 & $11 / 03$ & $11 / 04$ & -0.00013 \\
\hline MacAyeal $_{1}$ & 3 & 0.5 & -79.950 & $\begin{array}{r}-145.361 \\
0.000\end{array}$ & $\begin{array}{c}11 / 03 \\
3 / 05\end{array}$ & $\begin{array}{l}3 / 05 \\
3 / 08\end{array}$ & $\begin{array}{c}-0.44 \\
0.3\end{array}$ \\
\hline MacAyeal $_{2}$ & 2 & 0.4 & -79.833 & -144.078 & $10 / 04$ & $11 / 06$ & 0.16 \\
\hline MacAyeal $_{3}$ & 2 & 0.7 & -79.636 & -139.109 & $\begin{array}{c}11 / 03 \\
3 / 04\end{array}$ & $\begin{array}{c}3 / 04 \\
11 / 06\end{array}$ & $\begin{array}{r}-0.13 \\
0.21\end{array}$ \\
\hline MacAyeal $_{4}$ & 2 & 0.9 & -78.676 & -132.661 & $11 / 03$ & $10 / 07$ & -0.05 \\
\hline Mercer $_{1}$ & 4 & 0.7 & -84.602 & -154.191 & $\begin{array}{c}11 / 05 \\
3 / 07\end{array}$ & $\begin{array}{l}3 / 07 \\
2 / 08\end{array}$ & $\begin{array}{c}0.084 \\
-0.07\end{array}$ \\
\hline
\end{tabular}


Table 4. Continued

\begin{tabular}{|c|c|c|c|c|c|c|c|}
\hline Name & \# tracks & $R_{\text {constraint }}$ & $\begin{array}{l}\text { Lat. } \\
{ }^{\circ} \mathrm{N}\end{array}$ & $\begin{array}{c}\text { Long. } \\
{ }^{\circ} \mathrm{E}\end{array}$ & Start & End & $\begin{array}{c}\mathrm{d} V \\
\mathrm{~km}^{3}\end{array}$ \\
\hline Mercer $_{2}$ & 6 & 0.9 & -84.661 & -149.481 & $\begin{array}{c}11 / 03 \\
11 / 05 \\
6 / 06 \\
3 / 07\end{array}$ & $\begin{array}{c}11 / 05 \\
6 / 06 \\
3 / 07 \\
3 / 08\end{array}$ & $\begin{array}{c}0.43 \\
-0.36 \\
0.38 \\
-0.5\end{array}$ \\
\hline Ninnis $_{1}$ & 1 & 0.7 & -70.887 & 144.274 & $11 / 03$ & $3 / 08$ & 0.14 \\
\hline Mulock $_{1}$ & 2 & 0.9 & -78.091 & 149.108 & $10 / 03$ & $2 / 08$ & 0.06 \\
\hline Nimrod $_{1}$ & 2 & 1.0 & -83.488 & 150.276 & $11 / 03$ & $3 / 08$ & 0.031 \\
\hline Nimrod $_{2}$ & 16 & 1.0 & -84.325 & 141.004 & $11 / 03$ & $3 / 08$ & 1.1 \\
\hline Raymond $_{1}$ & 2 & 0.7 & -81.352 & -128.443 & $11 / 05$ & $3 / 08$ & 0.026 \\
\hline Recovery $_{1}$ & 9 & 0.3 & -81.148 & -29.076 & $11 / 03$ & $2 / 08$ & 2.2 \\
\hline Recovery $_{2}$ & 4 & 0.4 & -81.319 & -27.170 & $11 / 03$ & 10/07 & 0.45 \\
\hline Recovery $_{3}$ & 8 & 0.3 & -80.907 & -24.124 & $\begin{array}{c}11 / 03 \\
10 / 04 \\
6 / 05\end{array}$ & $\begin{array}{c}10 / 04 \\
6 / 05 \\
10 / 07\end{array}$ & $\begin{array}{r}0.16 \\
-0.26 \\
0.92\end{array}$ \\
\hline Recovery $_{4}$ & 2 & 0.7 & -81.324 & -20.052 & $\begin{array}{l}11 / 03 \\
10 / 04\end{array}$ & $\begin{array}{c}10 / 04 \\
3 / 08\end{array}$ & $\begin{array}{r}0.014 \\
-0.084\end{array}$ \\
\hline Recovery $_{5}$ & 5 & 0.8 & -81.284 & -9.608 & $\begin{array}{l}11 / 03 \\
11 / 06\end{array}$ & $\begin{array}{c}11 / 06 \\
3 / 08\end{array}$ & $\begin{array}{r}0.28 \\
-0.15\end{array}$ \\
\hline Recovery $_{6}$ & 4 & 0.9 & -81.429 & -7.273 & $11 / 03$ & 4/07 & 0.17 \\
\hline Recovery $_{7}$ & 5 & 0.9 & -81.644 & -5.979 & $11 / 05$ & $10 / 07$ & -2.1 \\
\hline Recovery $_{8}$ & 4 & 0.9 & -81.802 & -4.122 & $11 / 03$ & $4 / 07$ & -0.2 \\
\hline Recovery $_{9}$ & 5 & 1.0 & -82.914 & 2.336 & $10 / 04$ & $3 / 08$ & -0.22 \\
\hline Recovery $_{10}$ & 5 & 1.0 & -83.503 & 5.941 & $6 / 05$ & $3 / 08$ & -0.49 \\
\hline Recovery $_{11}$ & 5 & 0.9 & -81.716 & 8.417 & $\begin{array}{c}11 / 03 \\
4 / 07\end{array}$ & $\begin{array}{l}4 / 07 \\
3 / 08\end{array}$ & $\begin{array}{c}-0.2 \\
0.024\end{array}$ \\
\hline Rutford $_{1}$ & 1 & 0.7 & -78.182 & -84.173 & $\begin{array}{c}10 / 03 \\
5 / 05 \\
3 / 07\end{array}$ & $\begin{array}{l}5 / 05 \\
3 / 07 \\
2 / 08\end{array}$ & $\begin{array}{c}-0.043 \\
0.16 \\
-0.12\end{array}$ \\
\hline Slessor $_{1}$ & 4 & 0.2 & -80.037 & -25.272 & $\begin{array}{l}11 / 03 \\
11 / 05 \\
11 / 06\end{array}$ & $\begin{array}{c}11 / 05 \\
11 / 06 \\
3 / 08\end{array}$ & $\begin{array}{c}-0.23 \\
0.042 \\
-0.032\end{array}$ \\
\hline Slessor $_{2}$ & 2 & 0.7 & -79.836 & -21.563 & $11 / 03$ & $3 / 08$ & 0.77 \\
\hline Slessor $_{3}$ & 3 & 0.5 & -79.924 & -21.360 & $11 / 03$ & $11 / 05$ & -0.13 \\
\hline Slessor $_{4}$ & 3 & 0.8 & -79.336 & -17.085 & $10 / 03$ & $11 / 06$ & 0.29 \\
\hline Slessor $_{5}$ & 2 & 0.7 & -79.201 & -17.039 & $\begin{array}{l}3 / 04 \\
3 / 06 \\
4 / 07\end{array}$ & $\begin{array}{l}3 / 06 \\
4 / 07 \\
3 / 08\end{array}$ & $\begin{array}{c}-0.053 \\
0.03 \\
-0.032\end{array}$ \\
\hline Slessor $_{6}$ & 2 & 1.0 & -78.770 & -14.297 & $11 / 03$ & $10 / 07$ & -0.084 \\
\hline Slessor $_{7}$ & 3 & 0.7 & -79.250 & -11.050 & $3 / 05$ & $3 / 08$ & 0.28 \\
\hline Totten $_{1}$ & 2 & 0.8 & -70.103 & 107.501 & $\begin{array}{l}11 / 03 \\
10 / 05\end{array}$ & $\begin{array}{c}10 / 05 \\
3 / 08\end{array}$ & $\begin{array}{r}-0.86 \\
0.42\end{array}$ \\
\hline Totten $_{2}$ & 3 & 0.7 & -70.829 & 110.511 & $\begin{array}{c}11 / 03 \\
5 / 05 \\
11 / 06\end{array}$ & $\begin{array}{c}5 / 05 \\
11 / 06 \\
10 / 07\end{array}$ & $\begin{array}{c}-0.58 \\
0.4 \\
-0.31\end{array}$ \\
\hline Vostok $_{1}$ & 2 & 1.0 & -77.169 & 106.834 & $11 / 03$ & $3 / 08$ & -0.021 \\
\hline Whillans $_{1}$ & 8 & 0.4 & -83.731 & -157.419 & $\begin{array}{l}11 / 03 \\
11 / 05 \\
11 / 06\end{array}$ & $\begin{array}{l}11 / 05 \\
11 / 06 \\
10 / 07\end{array}$ & $\begin{array}{c}-1.8 \\
0.15 \\
-0.29\end{array}$ \\
\hline Whillans $_{2 a}$ & 5 & 0.6 & -84.035 & -160.271 & $\begin{array}{l}11 / 03 \\
11 / 05 \\
11 / 06\end{array}$ & $\begin{array}{l}11 / 05 \\
11 / 06 \\
10 / 07\end{array}$ & $\begin{array}{r}-0.045 \\
0.021 \\
-0.031\end{array}$ \\
\hline Whillans $_{2 \mathrm{~b}}$ & 5 & 0.7 & -84.343 & -158.196 & $10 / 03$ & $10 / 07$ & 0.081 \\
\hline Whillans $_{3}$ & 5 & 0.7 & -84.243 & -153.656 & $\begin{array}{c}11 / 03 \\
3 / 04 \\
6 / 06 \\
3 / 07\end{array}$ & $\begin{array}{l}3 / 04 \\
6 / 06 \\
3 / 07 \\
3 / 08\end{array}$ & $\begin{array}{c}-0.016 \\
0.15 \\
-0.092 \\
0.023\end{array}$ \\
\hline Whillans $_{4}$ & 10 & 0.8 & -84.374 & -148.719 & $\begin{array}{c}11 / 03 \\
6 / 06\end{array}$ & $\begin{array}{l}6 / 06 \\
3 / 08\end{array}$ & $\begin{array}{l}0.75 \\
-1.1\end{array}$ \\
\hline Whillans $_{5}$ & 8 & 0.7 & -84.091 & -146.071 & $\begin{array}{l}10 / 03 \\
10 / 04 \\
10 / 07\end{array}$ & $\begin{array}{c}10 / 04 \\
10 / 07 \\
2 / 08\end{array}$ & $\begin{array}{c}0.072 \\
-0.49 \\
0.026\end{array}$ \\
\hline Whillans $_{6}$ & 3 & 0.8 & -83.846 & -136.914 & $3 / 04$ & $11 / 06$ & -0.12 \\
\hline
\end{tabular}


Table 4. Continued

\begin{tabular}{|c|c|c|c|c|c|c|c|}
\hline Name & \# tracks & $R_{\text {constraint }}$ & $\begin{array}{l}\text { Lat. } \\
{ }^{\circ} \mathrm{N}\end{array}$ & $\begin{array}{l}\text { Long. } \\
{ }^{\circ} \mathrm{E}\end{array}$ & Start & End & $\begin{array}{c}\mathrm{d} V \\
\mathrm{~km}^{3}\end{array}$ \\
\hline Whillans $_{7}$ & 2 & 0.5 & -83.237 & -133.008 & $\begin{array}{c}11 / 03 \\
3 / 05 \\
3 / 06\end{array}$ & $\begin{array}{l}3 / 05 \\
3 / 06 \\
3 / 07\end{array}$ & $\begin{array}{r}0.053 \\
-0.028 \\
0.033\end{array}$ \\
\hline Whillans $_{8}$ & 3 & 1 & -83.504 & -113.601 & $\begin{array}{l}10 / 03 \\
10 / 07\end{array}$ & $\begin{array}{c}10 / 07 \\
2 / 08\end{array}$ & $\begin{array}{c}0.13 \\
-0.0081\end{array}$ \\
\hline $\begin{array}{l}\text { Wilkes }_{1} \\
\text { Wilkes }_{2}\end{array}$ & $\begin{array}{l}2 \\
1\end{array}$ & $\begin{array}{l}0.81 \\
0.54\end{array}$ & $\begin{array}{l}-68.812 \\
-68.703\end{array}$ & $\begin{array}{l}106.715 \\
121.566\end{array}$ & $\begin{array}{l}11 / 03 \\
11 / 03\end{array}$ & $\begin{array}{c}10 / 07 \\
4 / 07\end{array}$ & $\begin{array}{l}0.41 \\
0.077\end{array}$ \\
\hline
\end{tabular}

MS received 19 March 2009 and accepted in revised form 21 May 2009 